\title{
DEMONSTRATION OF POSTSYNAPTIC OPIOID MODULATION OF THALAMIC PROJECTION NEURONS BY THE COMBINED TECHNIQUES OF RETROGRADE HORSERADISH PEROXIDASE AND ENKEPHALIN IMMUNOCYTOCHEMISTRY ${ }^{1}$
}

\author{
M. A. RUDA, ${ }^{2}$ J. COFFIELD, AND R. DUBNER \\ Neurobiology and Anesthesiology Branch, National Institute of Dental Research, National Institutes of Health, \\ Bethesda, Maryland 20205
}

Received September 29, 1983; Revised February 13, 1984; Accepted February 17, 1984

\begin{abstract}
Thalamic projection neurons represent a major source of nociceptive information from the dorsal horn to higher centers of the neuraxis. The synaptic relationship between thalamic projection neurons and the opioid peptide enkephalin (ENK) was examined at the light (LM) and ultrastructural (EM) level using the combined techniques of retrograde transport of horseradish peroxidase and ENK immunocytochemistry. Utilizing two different chromogens to develop the peroxidase reaction product, the two labeled neural elements could be readily distinguished at the LM level in the same tissue section. In the medullary, cervical, and lumbar levels of the dorsal horn of both the cat and monkey, at least $30 \%$ of the thalamic projection neurons in lamina I were observed at the LM level to be contacted by ENK-immunoreactive varicosities. In lamina V, approximately $50 \%$ of the thalamic projection neurons received ENK contacts. Since some neurons were not observed to receive a dense ENK innervation on their somata and proximal dendrites, these data suggest that there may be different functional types of thalamic projection neurons. At the EM level, the ENK-immunoreactive varicosities were observed to form asymmetrical synaptic contacts on the labeled somata and proximal dendrites of the projection neurons. In all cases, the ENK varicosities were morphologically similar and contained round or oval agranular vesicles and a few dense-core vesicles. These observations suggest that ENK acts to a substantial degree on postsynaptic opiate receptors located on thalamic projection neurons.
\end{abstract}

The spinothalamic and trigeminothalamic tracts are responsible for the transmission of nociceptive information from the dorsal horn rostrally to higher centers of the neuraxis. It is primarily a contralateral system whose cells of origin are concentrated in laminae I and V of the dorsal horn (Carstens and Trevino, 1978; Hockfield and Gobcl, 1978; Burton and Craig, 1979; Giesler et al., 1979; Willis et al., 1979). The majority of neurons are either nociceptive-specific, responding exclusively to noxious stimuli, or wide dynamic range, responding to both noxious and non-noxious stimuli (Trevino et al., 1972; Willis et al., 1974; Price et al., 1976, 1979; Geisler et al., 1976; Kenshalo et al., 1979).

Enkephalin (ENK) is an opioid peptide which is one of the endogenous ligands for opiate receptors. It is present in all laminae of the dorsal horn but is most concentrated in laminae I, II, and V (Hokfelt et al., 1977; Sar et al., 1978; Uhl et al., 1979; Glazer and Basbaum, 1981; Hunt et al., 1981; Bennett et al., 1982). It originates mainly from intrinsic dorsal horn neurons (Seybold and Elde, 1980; Hunt et al., 1981; Ruda et al., 1983). Enkephalin has been shown to inhibit the responses of

\footnotetext{
${ }^{1}$ We wish to thank Emma Humphrey for her expert technical assistance, Drs. G. J. Bennett, M. Hoffert, V. Miletic, and T. Sugimoto for their careful review of the manuscript, and E. Welty for typing it.

${ }^{2}$ To whom correspondence should be addressed.
}

dorsal horn neurons to noxious stimulation and the behavioral response to noxious stimulation (Duggan et al., 1977; Yaksh et al., 1977; Randic and Miletic, 1978; Satoh et al., 1979; Zieglgansberger and Tulloch, 1979). Both a postsynaptic and a presynaptic mechanism of action have been proposed. The postsynaptic hypothesis is strongly supported by morphological observations which demonstrate that the preponderance of ENK varicosities form synapses on dendrites and cell bodies of dorsal horn neurons (Hunt et al., 1980; Aronin et al., 1981; Sumal et al., 1982, Glazer and Basbaum, 1983; LaMotte and deLanerolle, 1983). Physiological observations of the suppression of glutamate-evoked excitation by ENK (Zieglgansberger and Tulloch, 1979; Willcockson et al., 1984b) provide further support. Evidence in support of a presynaptic site of action of ENK derives from opiate receptor binding and electrophysiological studies on primary afferent fibers (LaMotte et al., 1976; Hiller et al., 1978; MacDonald and Nelson, 1978; Mudge et al., 1979; Fields et al., 1980; Nagy et al., 1980). However, the presynaptic hypothesis lacks morphological support in that double-label experiments have failed to identify synaptic contacts between labeled enkephalin and labeled primary afferent terminals (Hunt et al., 1980; Sumal et al., 1982).

In an effort to identify the postsynaptic site of action of opiates, we have investigated the potential synaptic interaction between thalamic projection neurons and ENK. Thalamic pro- 
jection neurons were labeled by retrograde transport of horseradish peroxidase (HRP), while ENK varicosities were identified with peroxidase-antiperoxidase (PAP) immunocytochemistry. The combination of these two techniques in the same experiment offered a unique approach to identifying the underlying components of dorsal horn neural circuitry involved in opiate modulation. We have been able to quantify the distribution of ENK contacts on thalamic projection neurons and have demonstrated at the EM level that these contacts are associated with synaptic specializations. The current study extends our previous analysis of ENK innervation of lamina $V$ thalamic projection neurons (Ruda, 1982) by examining projection neurons in other laminae of the cat in addition to comparing these findings to ENK innervation of the thalamic projection neurons in the monkey.

\section{Materials and Methods}

Experiments were conducted on five cats and two monkeys (Macaca mulatta). Several large injections of a $50 \%$ solution of HRP (Sigma, type VI) in distilled water were made into the thalamus using a $10-\mu$ l Hamilton syringe attached to a stereotaxic frame. The injection sites were selected from coordinates in the atlases of Snider and Neimer (1961) and Snider and Lee (1961). The pattern of cortical sulci and the depth of the thalamus below the cortical surface, as measured from a series of cresyl violet-stained sections of monkey brain, also served as a guide for placement of the needle tip. All animals except one cat received unilateral injections. Following the surgery, the animals were given penicillin and returned to their cages for a period of 3 to 4 days. Under deep sodium pentobarbital anesthesia, the animals were perfused through the heart with 4 liters of $4 \%$ paraformaldehyde and $0.2 \%$ glutaraldehyde in $0.1 \mathrm{M}$ phosphate buffer, $\mathrm{pH}$ 7.4. The brainstem and spinal cord were removed and placed in fresh fixative for a period of 1 to $4 \mathrm{hr}$ at $4^{\circ} \mathrm{C}$ and subsequently stored in $0.1 \mathrm{M}$ phosphate buffer at $4^{\circ} \mathrm{C}$. Transverse or sagittal sections of the medulla and spinal cord were cut at $50 \mu \mathrm{m}$ with a Vibratome. Immediately after sectioning, the tissue was processed with cobalt chloride-intensified diaminobenzidine hydrochloride (DAB) (Sigma) to mark the retrogradely labeled neurons with a black reaction product (Adams, 1977).

The thalamus was blocked in situ in the transverse stereotaxic plane and was sectioned at $100 \mu \mathrm{m}$ with a freezing microtome. The thalamic injection sites were localized using either the $\mathrm{DAB}$ reaction alone or in combination with cobalt chloride. Following the histochemical reaction, selected sections were counterstained with cresyl violet. Representative transverse sections through the rostrocaudal extent of the injection site in each animal are illustrated as camera lucida drawings in Figure 1.

To identify enkephalin profiles, sections containing the retrogradely labeled neurons were processed for immunocytochemistry using an antibody raised against leucine-enkephalin conjugated to bovine serum albumin (Immuno Nuclear Corp.) and the PAP staining technique of Sternberger (1979). In radioimmunoassay, this antiserum cross-reacts substantially with methionine-enkephalin but not with other species of opioid peptides. Free-floating sections were incubated in the ENK antisera at a dilution of $1: 12,000$ to $1: 15,000$ overnight at $4^{\circ} \mathrm{C}$ with gentle agitation, followed by goat anti-rabbit IgG (1:50) and PAP (1:80 light microscope (LM); 1:40 electron microscope (EM)) (SternbergerMeyer Immunochemicals, Inc.) at room temperature for $30 \mathrm{~min}$. The $1^{\circ}, 2^{\circ}$, and PAP diluents contained $1 \%$ normal goat serum (NGS) Between each change, the sections were rinsed in phosphate-buffered saline (PBS) and incubated for $30 \mathrm{~min}$ in 3\% NGS to reduce background staining. The immunocytochemical reaction product was developed in $0.05 \% \mathrm{DAB}$ with $0.01 \%$ hydrogen peroxide in $0.1 \mathrm{M}$ phosphate buffer for 6 to $12 \mathrm{~min}$ to produce a distinctive red-brown reaction product. As a control, some sections were incubated in antisera to enkephalin that had been preabsorbed with an excess of antigen (100 $\mu \mathrm{g} / \mathrm{ml}$ ) (Roehringer-Mannheim). The preabsorbed antisera yielded no positive immunoreactive staining. For light microscopy, the tissue was treated with $0.75 \%$ Triton $\mathrm{X}-100$ in the $1^{\circ}, 2^{\circ}$, and PAP incubation to ensure penetration of the antibody throughout the depth of the $50-\mu \mathrm{m}$ section. Complete penetration was ascertained by differential focusing through the section as well as examination of $1-\mu \mathrm{m}$ plastic-embedded sections cut through the thickness of the 50- $\mu$ m section several millimeters from its edge. For electron microscopy, no penetrating agents were used, resulting in a 1 - to $2-\mu \mathrm{m}$ window of immunocytochenical labeling on the surfaces of the sections.

For light microscopy, the sections were mounted on gelatin-coated slides and cleared in xylene. The tissue was examined with a $\times 100$ oil immersion objective lens for the presence of red-brown, immunocytochemically labeled profiles contacting the retrogradely labeled somata and proximal dendrites of projection neurons (Fig. 3). The amount of retrograde reaction product present in the projection neurons varied from intensely blackened neurons to neurons which contained only a few black granules (Fig. 3, $E$ to $G$ ). Since the reaction product was developed with the relatively insensitive DAB method, we suspect that many neurons with only slight amounts of retrogradely transported HRP were not visible. At the LM level in two animals, cat 5 and monkey 1 , the number of thalamic projection neurons which were contacted by ENK varicosities was tabulated (Table I). In the cat, all labeled neurons in 70 random transverse sections from different rostrocaudal levels of the medullary dorsal horn and 27 sagittal sections which spanned the length of the cervical enlargement were examined and counted. All retrogradely labeled neurons in the cervical enlargement and in 158 transverse sections from the lumbar enlargement of the monkey were evaluated and counted. In lamina I, the ENK staining pattern sometimes was too dense to allow unequivocal determination of the presence of an ENK contact onto a projection neuron. In such cases, the neuron was not included in our counts.

Viewed at the LM level, the apposition of two differentially labeled neural elements may represent potential sites of synaptic interaction. In our LM analysis, the apposition of ENK varicosities and projection neurons was termed a contact when, despite differential focusing, no space could be discerned between the two labeled elements when examined with $a \times 100$ oil immersion lens (Fig. $3, A$ and $B$ ). In our EM analysis, contacts between the two labeled elements ultimately formed synapses. Thus, contacts viewed at the LM level most likely represent sites of synaptic interaction. Thus, the number of contacts seen at the LM level would provide an index of the density of innervation onto the soma and proximal dendrites of an identified neuron.

Tissue sections used for electron microscopy were initially cleared by passage through a graded series of glycerin solutions to $100 \%$ glycerin and examined with the light microscope for the presence of red-brown, immunocytochemically labeled profiles contacting projection neurons marked with blackened HRP granules (Fig. $3 A$ ). Selected examples were sketched, and the location of the labeled cell was marked on the drawing as well as the approximate location of the ENK contacts. The best examples were obtained when the plane of section passed through the nucleus of the projection neuron, exposing its perimeter directly to the ENK antibodies. The sections were then postfixed for 1 $\mathrm{hr}$ in $2 \%$ osmium tetroxide in $0.1 \mathrm{M}$ phosphate buffer, dehydrated in a graded series of ethanol solutions, and flat embedded in Epon-Araldite resin (Polysciences, Inc.) between a plastic slide and coverslip. The sections were again examined with the light microscope following polymerization of the resin, the labeled neuron was relocated, and the tissue was mounted onto a blank chuck with fresh resin and repolymerized. The tissue was then trimmed to an EM block face just slightly larger than the labeled neuron while viewing the cell under a dissecting microscope. Serial thin sections were cut, collected on Formvar-coated slot grids, and examined with a Zeiss EM 10C electron microscope. Selected sections were examined before counterstaining with lead citrate since in these unstained sections the electron-dense $D A B$ reaction product stood out against a pale unlabeled neuropil, allowing unequivocal recovery of the retrogradely labeled neuron and ENK varicosities.

The differential ultrastructural staining pattern of ENK-immunoreactive somata and retrogradely labeled neurons was ascertained in single-labeled material which contained either a retrogradely labeled neuron or a PAP-labeled neuron. Ultrastructurally, the PAP immunoreactivity and retrograde HRP granules were observed to be differentially sequestered as described by others (LaVail and LaVail, 1975; Aronin et al., 1981; Glazer and Basbaum, 1983). The retrograde HRP was confined to membrane-bound organelles which included lysozomes and multivesicular bodies (Fig. 5). The FNK-immunoreactive somata contained areas of flocculent PAP reaction product which was not limited to discrete subcellular organelles. Axonal staining was attributed exclusively to ENK immunocytochemical labeling since tissue examined after development of the retrograde marker alone showed no axonal labeling extending beyond what appeared to be the initial segment of the projection neurons' axon. In addition, in single-label immunocytochemical experiments in which only ENK profiles were 


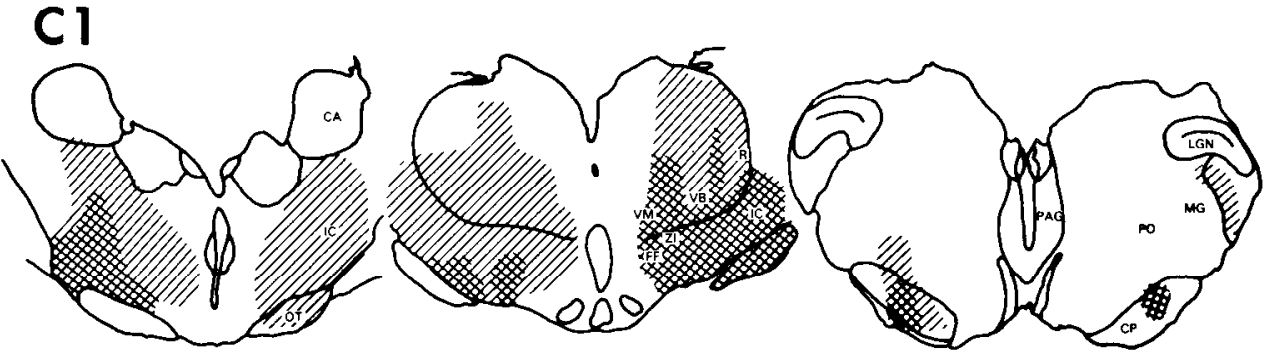

C2
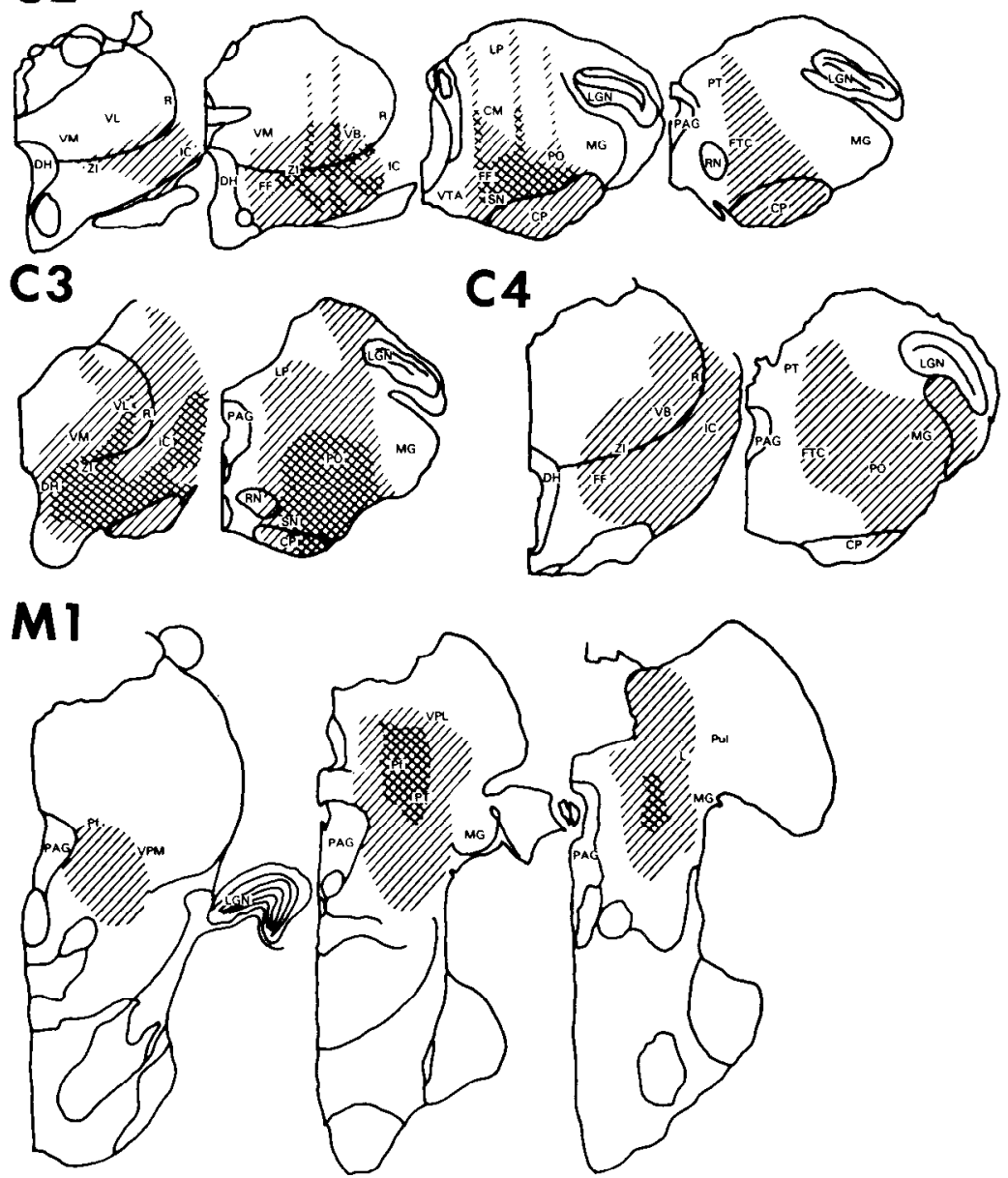

Figure 1. Camera lucida drawings of cresyl violet-stained sections of the rostrocaudal extent of the injection sites in four cats $(C 1$ to $C 4)$ and one monkey $(M 1)$. The densest locus of HRP reaction product is indicated by cross-hatching. $C A$, caudate nucleus; $C M$, centre median nucleus; $C P$, cerebral peduncle; CUN, nucleus cuneiformis; $D H$, dorsal hypothalamic nucleus; $F F$, nucleus of the fields of Forel; $F T C$, central tegmental fields; $I C$, internal capsule; $L$, nucleus limitans; $L G N$, lateral geniculate nucleus; $L P$, lateral posterior nucleus; $M G$, medial geniculate nucleus; $O T$, optic tract; $P A G$, periaqueductal gray; $P F$, nucleus parafascicularis; $P O$, posterior complex of the thalamus; $P T$, pretectal area, $P I J L$, pulvinar; $R$, reticular complex of the thalamus; $R N$, red nucleus; $S C$, superior colliculus; $S N$, substantia nigra; $V B$, ventrobasal complex; $V L$, ventrolateral complex; $V M$, ventromedial nucleus; $V P L$, nucleus ventralis posterior lateralis; $V T A$, ventral tegmental area of Tsai; $Z I$, zona incerta.

stained, numerous examples of ENK varicosities outlining the somata and dendrites of neurons in laminae I and V were found (Fig. 2).

At the EM level in the cat, we examined nine projection neurons in lamina I (seven medulla and two lumbar) and five in lamina $V$ (five medulla). In the monkey, we examined two lamina $V$ projection neurons (one medulla, and one lumbar). In some instances, approximately onehalf of the cell body, as indicated by the presence of a nucleolus in the nucleus, was examined in semiserial thin sections. Measurements of cell body diameter were made at a point in the cell at which the nucleolus was present.

\section{Results}

ENK-immunoreactive axonal endings were observed to contact retrogradely labeled thalamic projection neurons in the medullary dorsal horn and cervical and lumbar enlargements of both the cat and monkey. Most of the projection neurons receiving the ENK input were located in laminae $I$ and $V$. Within the population of projection neurons, a differential number of ENK contacts was observed. This distinctive pattern 

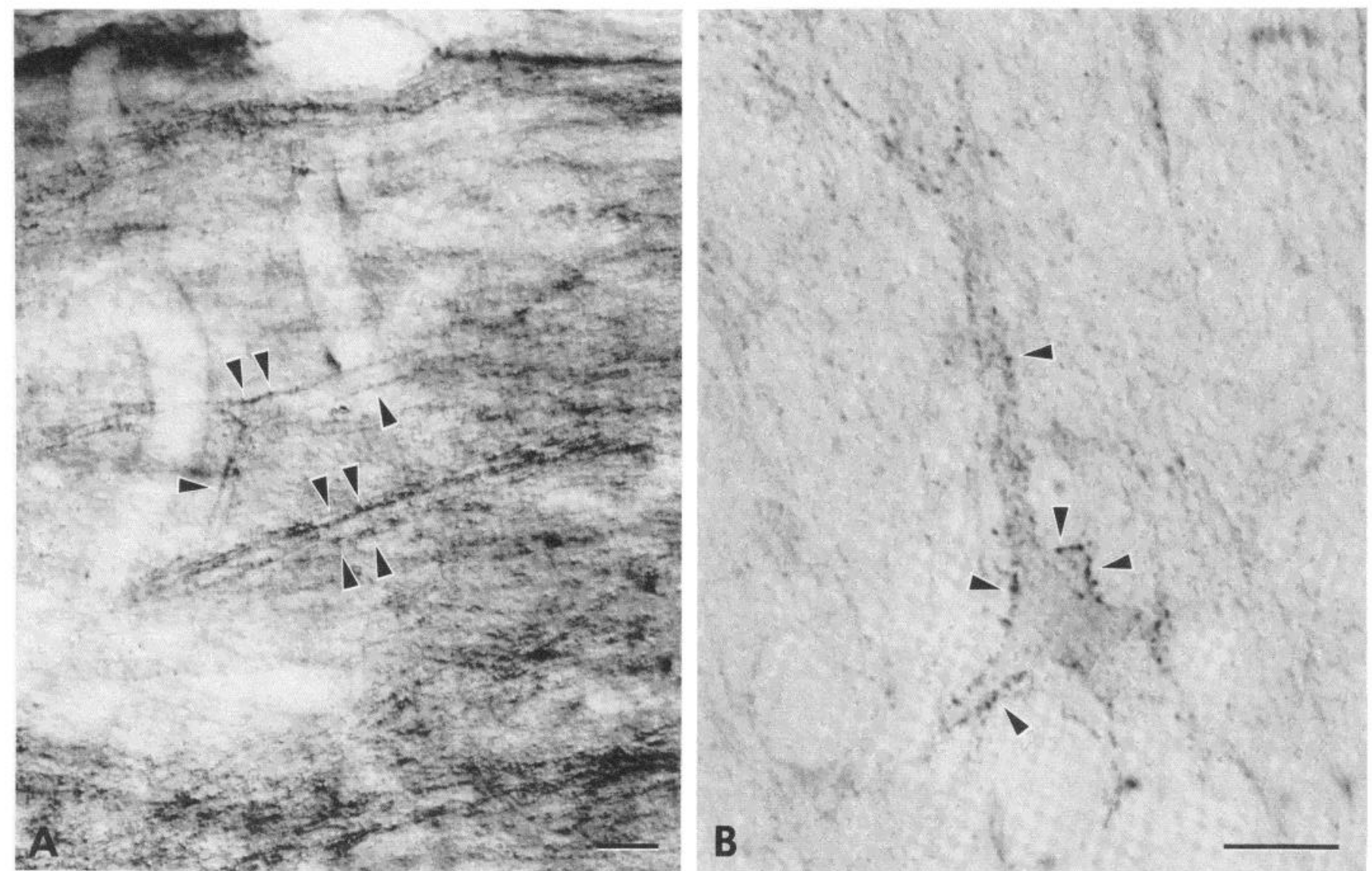

Figure 2. ENK-immunoreactive varicosties appeared to contact the proximal portions of neurons densely in single-label experiments in which the tissue was reacted only for ENK. A, Lamina I of the cervical enlargement of the monkey in the sagittal plane exhibited ENK varicosities which seemed to outline larger caliber dendritic shafts (arrowheads). The section plane passes through the most lateral part of the dorsal horn so that lamina I forms a wide band encompassing the entire field of the photomicrograph. Nomarsky optics help to accentuate the immunocytochemical reaction product, imparting a three-dimensional appearance. Magnification $\times 144$. The scale bar represents $50 \mu \mathrm{m}$. $B$, In lamina V, the cell soma and dendrites of neurons were outlined by ENK-immunoreactive varicosities which appear as blackened varicosities (arrowheads). These neurons often had a dorsally directed dendrite which entered lamina IV. This example was taken from the cat MDH. Magnification $\times$ 1544. The scale bar represents $10 \mu \mathrm{m}$.

of innervation was only loosely related to the morphology or laminar location of the thalamic projection neurons.

The two labeled neural elements were readily distinguished at the LM level by the two different chromogens: black granules in the projection neurons and red-brown PAP reaction product in the immunocytochemically labeled ENK varicosities (Fig. 3 ). At the EM level they could be distinguished by the diffuse flocculent nature of the PAP reaction product versus the dense retrograde HRP which was located within membrane-bound vesicular organelles (Fig. 5).
Thalamic injection site. The extent of the HRP injection site varied somewhat in each of the animals studied (Fig. 1). The injection sites were intentionally large in an attempt to label as many projection neurons as possible. Rostrocaudally, all of the injection sites covered several millimeters and were centered around the ventrobasal complex of the thalamus but not extending caudal to the magnocellular part of the medial geniculate body. The injection sites were localized to the more lateral parts of the thalamus, and in only one case (see Fig. 1, cat C3) did they encroach upon the midline nuclei. All injection sites

Figure 3. Retrogradely labeled thalamic projection neurons and immunocytochemically labeled ENK varicosities. $A$, At the LM level in glycerin-cleared sections, the two labels can be readily distinguished by their respective chromogens. The retrograde HRP granules appear blueblack and the ENK endings red-brown (arrows). This lamina V neuron was cut through the soma which is outlined with ENK-immunoreactive varicosities that extend onto the dendrite on the left, which is viewed from above. Differential focusing demonstrated that the ENK varicosities actually contacted the dendrite. The cell's nucleus is the central clear area. $B$, Phase contrast photomicrograph of a 1- $\mu \mathrm{m}$ plastic section of the same neuron as in $A$. The retrograde HRP is sequestered in small round granules dispersed in the cell's cytoplasm exclusive of the nucleus. The ENK-immunoreactive varicosities were typically larger and more elongated than the retrograde granules and appeared to abut the surface membrane of the cell directly (Arrows indicate the same varicosities as in $A$ ). $C$, Low magnification view of a retrogradely labeled neuron (arrow) in the middle of lamina $\mathrm{V}$ of the MDH which has been reacted for ENK immunocytochemistry. The pattern of ENK contacts on this cell is illustrated in Figure $7 E$. D , Nomarsky optics photomicrograph of a lamina I projection neuron in cat MDH that received two ENK contacts on its soma (arrow). Lamina I projection neurons typically did not have as dense a somatic ENK innervation as was often found on lamina $\mathrm{V}$ projection neurons. $E$ to $G$, The density of retrograde label in the projection neurons varied greatly (compare cells 1 and 2 ). Cells 1 and 2 lie adjacent to each other in lamina $\mathrm{V}$ of the cat $\mathrm{MDH}(F) . E$ and $G$ are enlargements of the cells in $F$. Often, the more lightly labeled projection neurons (i.e., cell 1) received the greatest number of ENK contacts. The intensely retrogradely labeled cell (2) is not contacted by ENK varicosities. This example uses Nomarsky optics to enhance the label. 

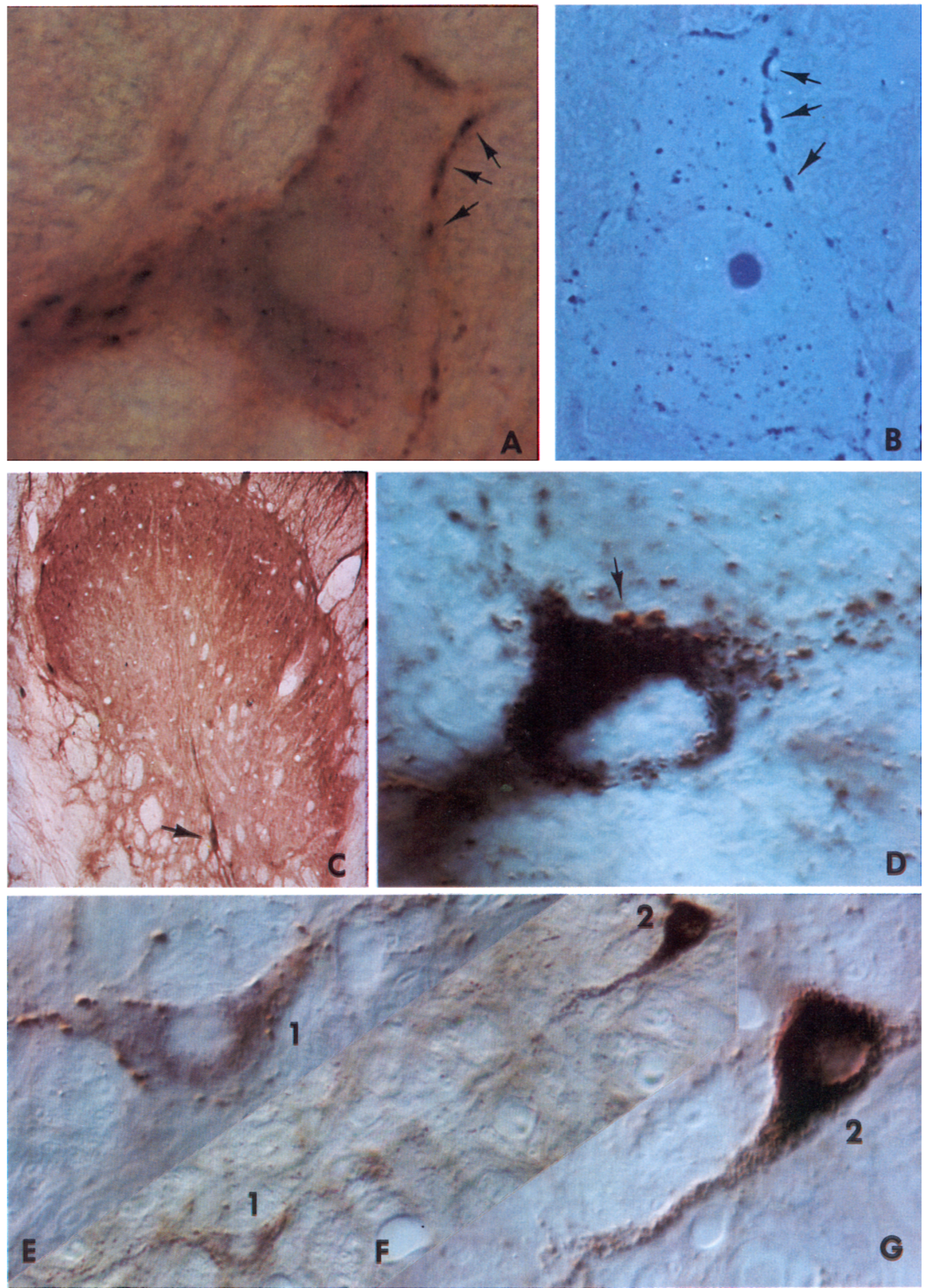
resulted in labeled neurons which received a variable number of ENK contacts. Thus, some neurons which are innervated by ENK varicosities most likely send at least part of their terminal axonal arbor to the lateral thalamus.

The retrogradely labeled projection neurons contained a variable amount of reaction product. Even in the same tissue section, adjacent neurons exhibited a differential intensity of staining (Fig. $3 F$ ). In lamina $\mathrm{V}$, some of the most lightly labeled neurons also received the greatest number of contacts from immunocytochemically labeled ENK varicosities (Fig. $3, A$ and $E)$. In contrast, the most darkly labeled projection neurons

TABLE I

Percentage of thalamic projection neurons contacted by ENKimmunoreactive axonal endings

\begin{tabular}{ccccc}
\hline & \multicolumn{2}{c}{ Cat } & \multicolumn{2}{c}{ Monkey } \\
\cline { 2 - 3 } \cline { 5 - 6 } & $\mathrm{MDH}$ & $\begin{array}{c}\text { Cervical } \\
\text { Enlargement }\end{array}$ & $\begin{array}{c}\text { Cervical } \\
\text { Enlargement }\end{array}$ & $\begin{array}{c}\text { Lumbar } \\
\text { Enlargement }\end{array}$ \\
\hline $\begin{array}{c}\text { Lamina I cells, } \\
\text { with contacts } \\
\text { Lamina I cells, } \\
\text { no contacts }\end{array}$ & $30 \%\left(26^{a}\right)$ & $50 \%(10)$ & $33 \%(45)$ & $50 \%(13)$ \\
$\begin{array}{c}\text { Lamina V cells, } \\
>10 \text { contacts }\end{array}$ & $31 \%(37)$ & $17 \%(7)$ & $40 \%(41)$ & $30 \%(5)$ \\
$\begin{array}{c}\text { Lamina V cells, } \\
2 \text { to 10 contacts }\end{array}$ & $26 \%(31)$ & $30 \%(13)$ & $27 \%(28)$ & $35 \%(6)$ \\
$\begin{array}{c}\text { Lamina V cells, } \\
\text { no contacts }\end{array}$ & $43 \%(50)$ & $53 \%(22)$ & $33 \%(34)$ & $35 \%(6)$ \\
\hline
\end{tabular}

${ }^{a}$ Numbers in parentheses are the number of neurons in the sample. were almost never heavily contacted by ENK varicosities (Fig. $3 G$ ). Rather, they received few ENK contacts, often out on their dendrites. In lamina I, the amount of retrograde reaction product was also variable among the labeled neurons. However, no striking preference for ENK contacts on the more lightly labeled neurons was observed. The variable density of retrograde labeling of the neurons in our sample may, in part, reflect the amount of axonal plexus that distributed within the confines of the injection site.

Lamina I thalamic projection neurons. Lamina I projection neurons in both the medullary (MDH) and spinal (SDH) dorsal horns of cat and monkey were contacted by ENK varicosities. The projection neurons were located at varying sites along the curve of the MDH but were particularly numerous in that part of lamina I that is somewhat separated from the rest of the dorsal horn by the spinal tract of $\mathrm{V}$. In the $\mathrm{SDH}$, they appeared to be concentrated under Lissauer's tract. The projection neurons receiving ENK input represented roughly one-third of the total population of lamina I projection neurons we examined (Table I). They included large and small bipolar neurons, as well as an occasional multipolar neuron (Fig. 4). Some of the larger (shortest diameter 20 to $30 \mu \mathrm{m}$ ) lamina I projection neurons received the greatest number of contacts from ENK profiles, while the small (shortest diameter 10 to $15 \mu \mathrm{m}$ ) bipolar projection neurons received few if any contacts (Fig. 5). Although most of the retrogradely labeled lamina I neurons contained reaction product only in their somata, some neurons were labeled out into their proximal dendrites (Fig. 4). We observed that the proximal dendrites and the somata of some of these neurons received numerous contacts which outlined the perimeter of the cell soma and dendrites (Fig. 4, $A$ and $E$ ).

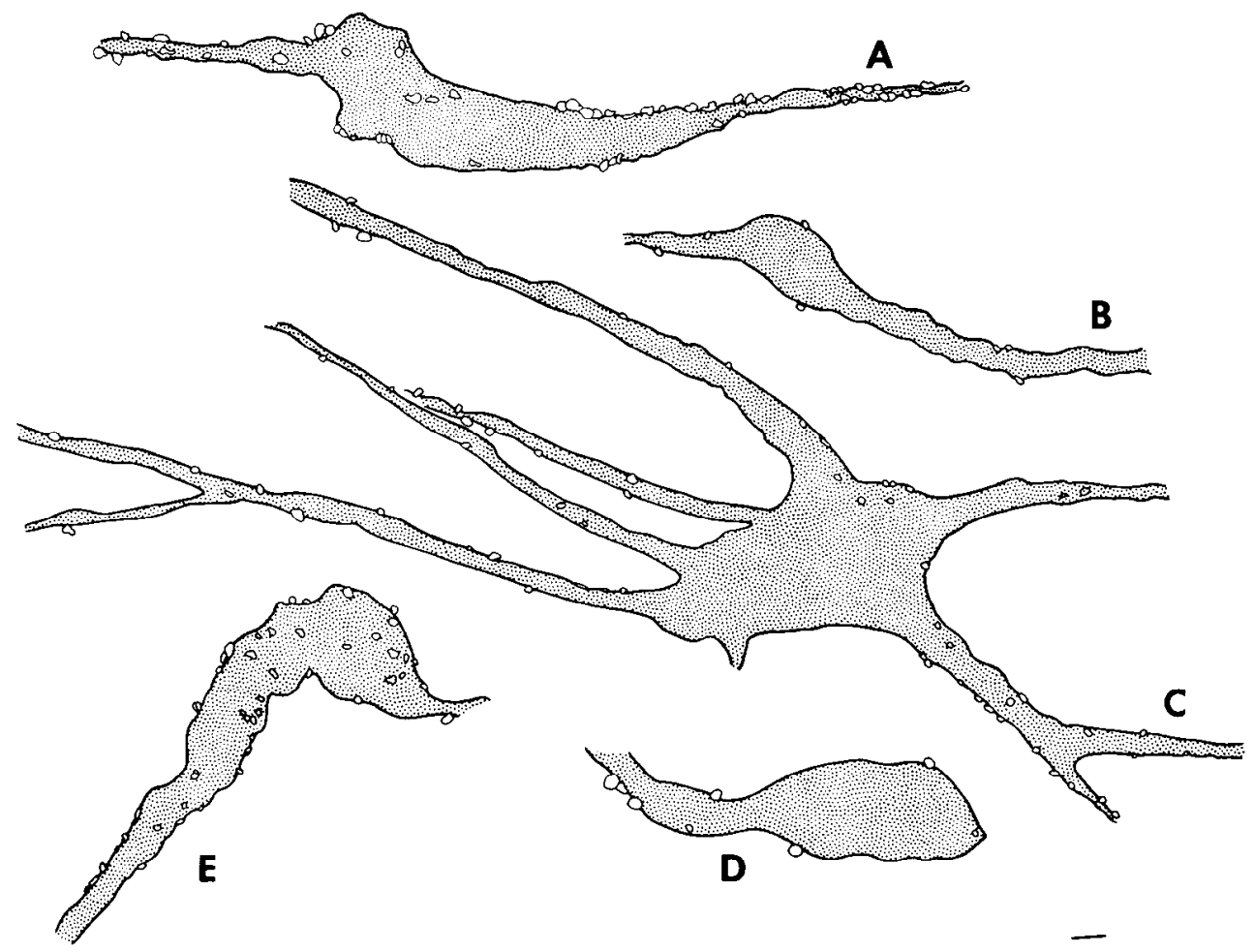

Figure 4. Camera lucida drawings of lamina I thalamic projection neurons (stippled) and ENKimmunoreactive varicosities (draun in outline) from the cat $\mathrm{MDH}$ in the transverse plane $(A$ and $B$ ), monkey cervical enlargement in the sagittal plane $(C)$, and monkey lumbar enlargement in the transverse plane $(I)$ and $E$ ). The number of somatic ENK-immunoreactive contacts was variable (compare $B$ and $D$ ) with $A$ and $E$ ), and in some cases no somatic ENK contacts were found (not illustrated). Some neurons preferentially received contacts on their dendrites $(C)$. The scale bar represents $10 \mu \mathrm{m}$. 
This type of relationship represented only a small proportion of the lamina I neurons in our sample. It was more common to see lamina I projection neurons with three or fewer ENK contacts on their somata and an additional three or four ENK contacts on their proximal dendrites (Fig. 4, $B$ and $D$ ). Additionally, some lamina I projection neurons (approximately twothirds of the total sample, see Table I) were not observed to be contacted by ENK profiles on their somata or labeled dendrites. These observations suggest that the lamina I thalamic projection neurons, which receive ENK input proximally, represent a subpopulation of all lamina I projection neurons. Additionally, our observations indicate that there is a differential proximal density of ENK input onto neurons in this class. Some lamina I thalamic projection neurons receive numerous ENK contacts, some receive few, and some were not contacted at all.

Ultrastructural analysis of lamina I projection neurons in the cat confirmed our LM observation of ENK contacts onto the retrogradely labeled neurons (Fig. $5 \mathrm{~A}$ ). The ENK varicosities were dome-shaped, ranged from 0.8 to $2.8 \mu \mathrm{m}$ along their long axes, and formed slightly asymmetrical synaptic contacts (Fig. 6 ). They contained mainly round or oval agranular vesicles and an occasional dense-core vesicle (Fig. 6). The PAP reaction product was associated with each of these vesicle types as well as the outer mitochondrial membrane. What appeared to be ENK-immunoreactive intervaricose portions of unmyelinated axons were commonly encountered in the vicinity of the ENK varicosity (Fig. $5 A$ ). In serial section analysis, the ENK varicosity could sometimes be traced back to such a labeled profile.

A bipolar lamina I projection neuron which received numerous ENK synapses is illustrated in Figure $5 \mathrm{~A}$. The neuron measured $35 \times 22 \mu \mathrm{m}$ and had a slightly indented nucleus and an occasional short, stubby somatic spine. On the half of the cell that was semiserially examined, $14 \mathrm{ENK}$-immunoreactive varicosities made synaptic contact. This number is an underestimate of the total somatic ENK input since the limited penetration of the antibody confined the immunoreactivity to 1 to $2 \mu \mathrm{m}$ on the surface of the section. The ENK profiles contacting this neuron were far outnumbered by unlabeled, vesicle-containing varicosities (Fig. $5 A$, inset). Some of these were dome-shaped and synapsed only on the labeled neuron, while others were central endings with a surrounding glomerulus formed of multiple synapses on adjacent unlabeled dendrites as well as the cell soma. A large number of the unlabeled varicosities contained pleomorphic agranular vesicles. However, some contained round or oval vesicles and were morphologically identical to the ENK immunoreactive profiles. This observation suggests that some unlabeled endings with round or oval vesicles which synapse on projection neurons contain a neurotransmitter other than ENK.

In addition to this rather large thalamic projection neuron, we examined four small thalamic projection neurons in lamina I whose short diameters ranged from 10 to $15 \mu \mathrm{m}$. Although our LM analysis demonstrated that some small thalamic projection neurons received a few ENK somatic contacts, the four neurons we examined ultrastructurally were not observed at the LM level to have ENK contacts. We were unable to recover ENK contacts onto any small projection neurons in tissue sections processed for EM immunocytochemistry. This failure may be due in part to a fundamentally different somatic innervation pattern between the large and small projection neurons we examined. In contrast to the numerous somatic contacts on the large projection neuron, all small projection neurons in our sample were sparsely innervated on their somata (Fig. $5 B$ ). The paucity of somatic contacts on these cells would greatly reduce the likelihood that one would be in the small window of immunoreactivity present in our EM tissue, thus reducing our chance of recovering an ENK contact. These small cells were characteristically ensheathed by glial processes which were full of filaments. 'They received two or three synaptic contacts on an isolated part of their perimeters, often at the base of their primary dendrites. Most of the axonal endings contacting the cells had pleomorphic vesicles (Fig. $5 B$ ), although an occasional round or oval vesicle-containing ending resembling the ENK endings was also present. Synaptic contacts were symmetrical or slightly asymmetrical and occasionally exhibited a prominent subsynaptic density.

Lamina $V$ thalamic projection neurons. Lamina $\mathrm{V}$ thalamic projection neurons in the cat and monkey represented the largest class of neurons which received ENK contacts $(>50 \%$ of the total number of projection neurons in a given lamina; see Table I). They were located in the lateral to middle (Fig. $3 C$ ) part of lamina $\mathrm{V}$ and were sometimes found in the adjacent lateral white matter at both $\mathrm{MDH}$ and SDH levels. Although both multipolar and bipolar projection neurons were labeled, most of the neurons which received ENK contacts were multipolar in shape (Fig. 7). The density of ENK contacts was variable on a given cell type. Many of the large multipolar neurons were often encrusted with $E N K$ varicosities along their somata in lamina $\mathrm{V}$ (Fig. $7, A$ and $E$ ) and their dendrites which could be followed dorsally into lamina IV and ventrally into lamina VI (Figs. $3 C$ and $7 E$ ). A second group of multipolar neurons received few proximal contacts which were distributed widely separated on their somata and proximal dendrites (Fig $7, B$ and $C$ ). The occasional bipolar neuron that received an ENK contact usually had only one or two contacts on its soma or out on its dendrites (Fig. $7 D$ ).

We observed ENK contacts onto more than half of the labeled projection neurons in lamina $\mathrm{V}$. Although most of the neurons which did not have ENK contacts were of the bipolar type, a significant number were multipolar and in all respects morphologically identical to the multipolar neurons which received ENK contacts. These observations suggest that we are not dealing with a homogeneous population of projection neurons. Rather, despite the morphological similarities, a functional difference must exist with respect to ENK modulation in lamina $\mathrm{V}$.

A total of seven lamina $\mathrm{V}$ thalamic projection neurons were examined ultrastructurally. Six cells were multipolar neurons which received synapses from ENK varicosities. At least 5 ENK varicosities and as many as $31 \mathrm{ENK}$ varicosities were recovered contacting these neurons at the EM level. The morphology of the ENK varicosities was essentially identical to that in lamina I. The endings contained round or oval agranular vesicles (Figs. 8 and 9), a few dense-core vesicles (Fig. 9), and large round clear vesicles (Fig. 8 ). The PAP reaction product was often unevenly distributed within the ending, and in serial sections of some endings large aggregates of vesicles in isolated areas were devoid of reaction product (Figs. $8 B$ and 9). The ENK varicosities typically formed an asymmetrical synapse which sometimes displayed a prominent subsynaptic density (Fig. $8 B$ ). The synaptic specialization occupied only a small portion of the surface area of the ENK varicosity which abutted the cell surface. Occasionally, the larger ENK varicosities were observed in serial sections to form more than one synaptic specialization as well as a punctum adhaerens on the same neuron (Fig. 8B).

In addition to the ENK varicosities, the multipolar neurons (Fig. 10A) in lamina $\mathrm{V}$ were typically surrounded by numerous unlabeled varicosities which contained either round, oval, or pleomorphic agranular vesicles. As in lamina I some of these unlabeled endings were morphologically similar to the labeled ENK varicosities. However, since they were not immunocytochemically labeled, they likely contain a different neurotransmitter.

The multipolar neurons which received ENK input had a moderate cytoplasmic density and either an unindented or 


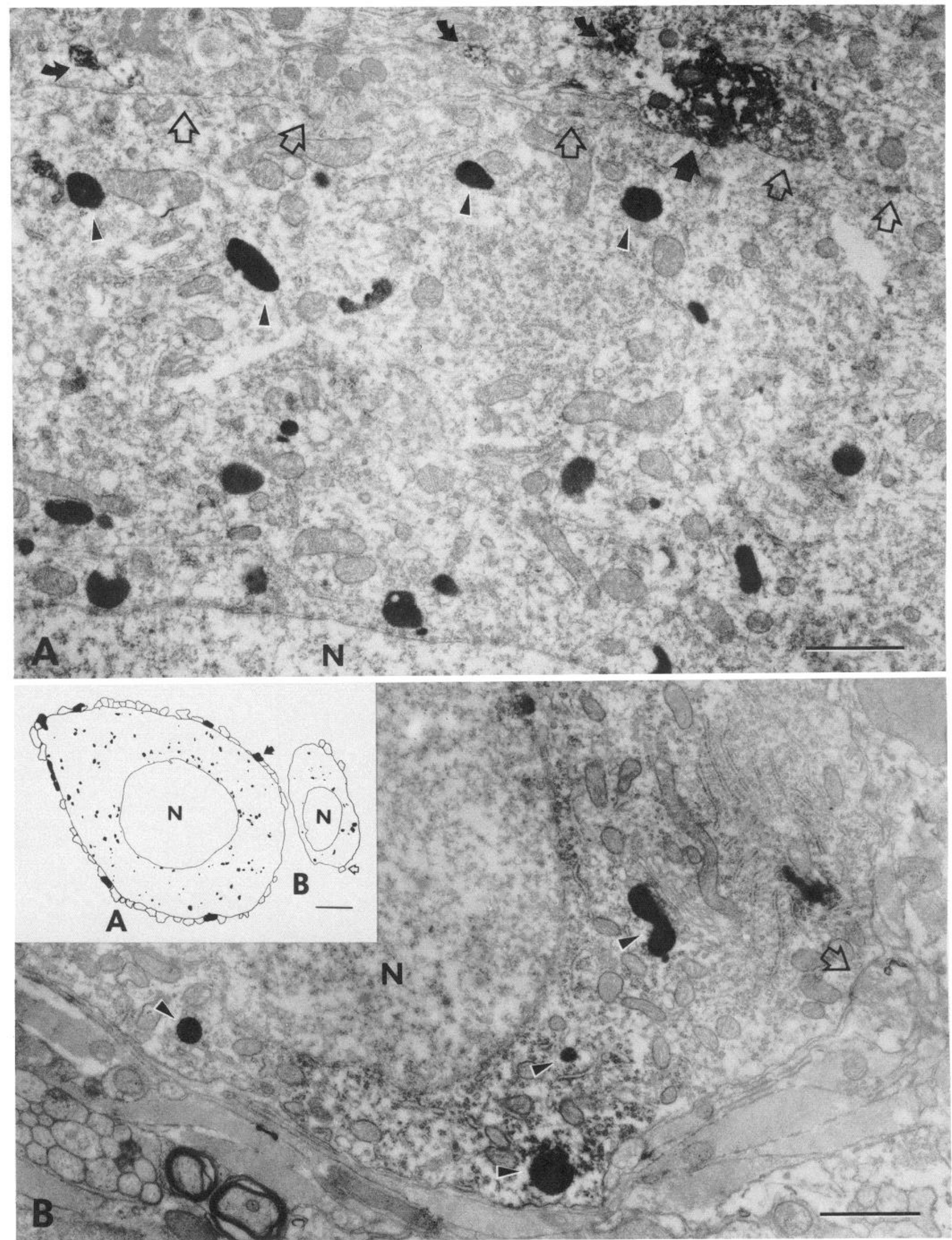



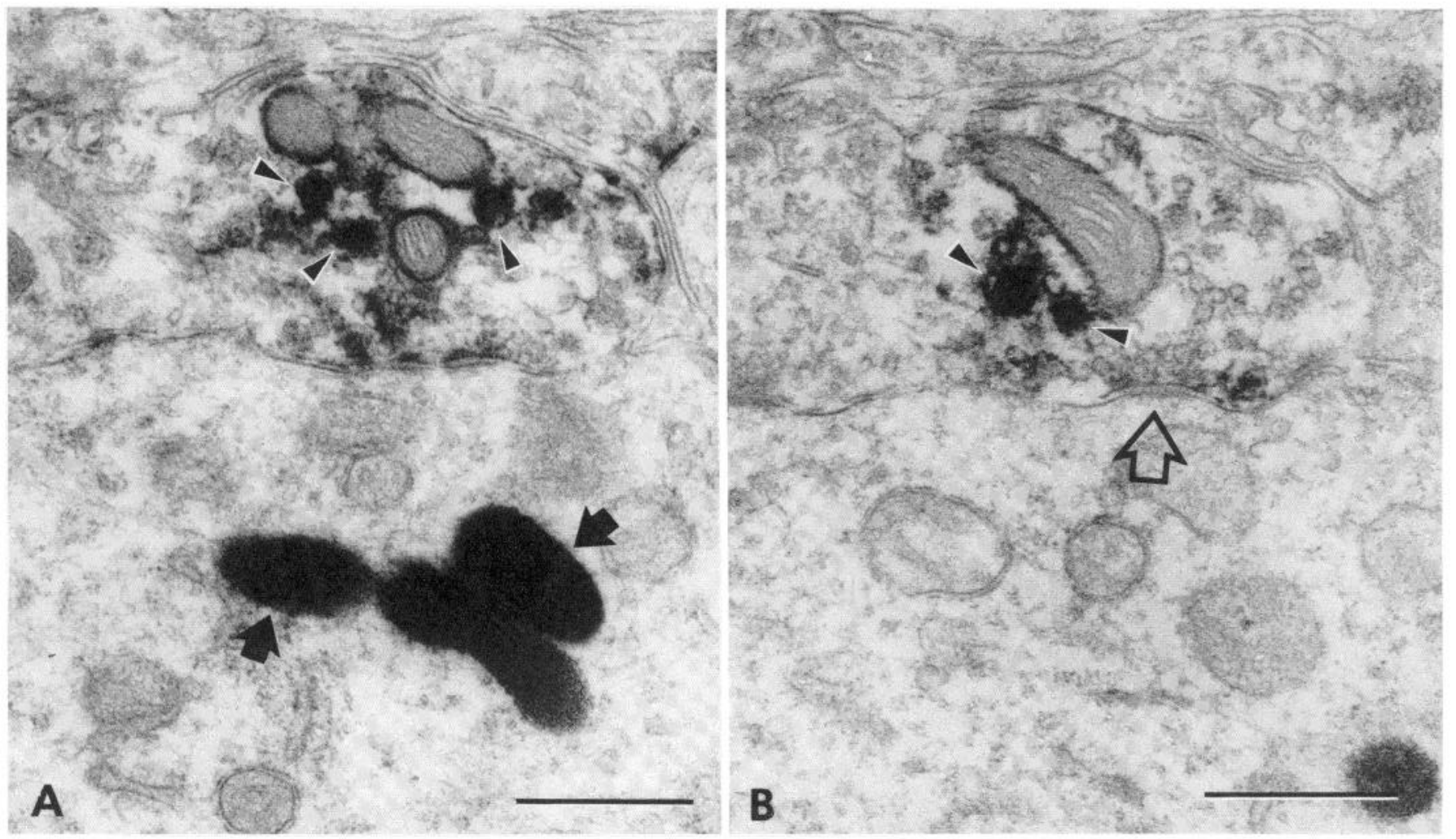

Figure 6. In lamina I, all ENK-immunoreactive varicosities which synapsed on thalamic projection neurons were morphologically similar. They contained oval agranular synaptic vesicles and a few dense-core vesicles. The PAP reaction product was sometimes associated with the dense-core vesicles preferentially (arrowheads). $A$ and $B$ represent sections through the same ENK-immunoreactive varicosity. The view in $A$ exhibits the beginnings of a membrane specialization which develops into a slightly asymmetrical synapse in $B$ (open arrow). Retrograde HRP reaction product is present in the portion of the cell shown in $A$ (solid arrows). This thalamic projection neuron is located in the cat MDH. Magnification for $A$ and $B, \times 49,200$. The scale bar represents $0.5 \mu \mathrm{m}$.

slightly indented nucleus with a prominent nucleolus. The cell soma long diameter ranged from 25 to $40 \mu \mathrm{m}$. A few somatic spines were present, and in one instance spines were observed to receive synapses from an ENK varicosity (Fig. 9). Although our sample of multipolar lamina $\mathrm{V}$ projection neurons included cells from both the MDH and SDH, no apparent morphological differences were detected. Additionally, the morphological observations were essentially identical in both the cat and monkey.

One bipolar lamina $\mathrm{V}$ projection neuron was examined at the EM level (Fig. 10B). This cell was typical of those which were observed, at the LM level, to be contacted occasionally by ENK varicosities. At the ultrastructural level, we did not recover any ENK contacts on this neuron. In contrast with the glia-ensheathed small bipolar projection neurons in lamina I, this neuron received numerous synaptic contacts from unlabeled varicosities along its soma and proximal dendrite.

Thalamic projection neurons in other laminae of the spinal cord. Retrogradely labeled projection neurons were observed at the LM level in laminae II, VI, VII, VIII, and X of the cervical and lumbar enlargements of both species. Projection neurons in laminae VII in the cat and monkey lumbar and cat cervical spinal cord were numerous while projection neurons in the other laminae were few in number. In contrast to projection neurons in laminae I and V, the labeled neurons in these other laminae uniformly received few if any contacts from immunocytochemically labeled ENK varicosities. These projection neurons were never found to be densely innervated by ENK terminals along their somata and proximal dendrites. Rather, an occasional ENK varicosity was observed at the LM level to contact the soma or a labeled proximal dendritic branch at some distance from the soma.

These observations of differential ENK innervation of projection neurons in different laminae suggest that thalamic projection neurons have unique distinguishing functional characteristics. A subpopulation of thalamic projection neurons in

Figure 5. Ultrastructural view of two thalamic projection neurons from cat MDH which vary with respect to the size of their cell soma. The neuron in $A$ had a large cell body which received synapses from numerous axonal endings (open arrows), one of which is immunocytochemically labeled for ENK (solid arrow). Several immunoreactive profiles which appear to be the intervaricose portion of unmyelinated axons were nearby (curved arrows). The retrograde HRP granules (arrowheads in A and B) are electron-dense and distributed in the cell cytoplasm exclusive of the nucleus $(N)$. In addition to $9 \mathrm{ENK}$-immunoreactive varicosities in this single thin section, this neuron's soma was surrounded by 46 other unlabeled axonal endings (inset). In contrast, the neuron shown in $B$ was a relatively small projection neuron whose soma was primarily ensheathed in a glial process which contained filaments and received few axonal contacts (open arrow). Magnification for $A$ and $B, \times 19,300$. The scale bar represents $1.0 \mu \mathrm{m}$. The inset is line drawings representing a tracing of a photomontage reconstruction of a single ultrathin section from each of the two projection neurons in the EM photomicrographs. The retrograde HRP granules and axonal endings which contacted the cells are drawn as viewed through the microscope with a $\times 100$ oil immersion objective. ENK-immunoreactive varicosities are blackened, and nonimmunoreactive varicosities are shown in outline. Arrows indicate the approximate site of axonal contacts shown in $A$ (solid arrow) and $B$ (open arrow). The scale bar represents $5.0 \mu \mathrm{m}$. 


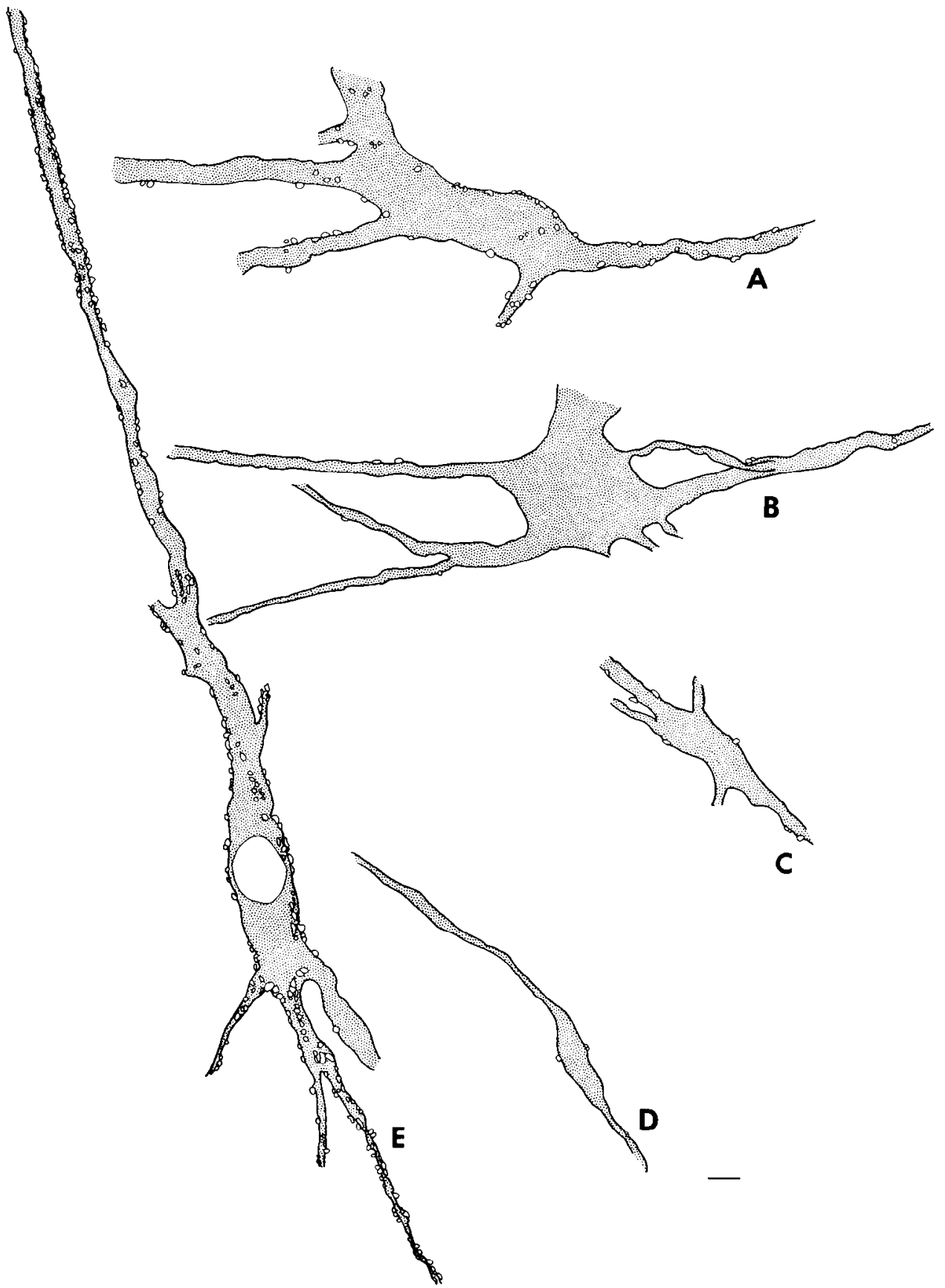

Figure 7. Camera lucida drawings of lamina $\mathrm{V}$ thalamic projection neurons (stippled) and ENK-immunoreactive varicosities (drawn in outline) from the monkey lumbar $(A)$ and cervical $(B$ and $C$ ) enlargements in the sagittal plane and cat MDH $(D$ and $E)$ in the transverse plane. The density of proximal ENK contacts varied greatly in lamina V. Some multipolar neurons $(A$ and $E)$ received numerous somatic and dendritic contacts, while others had few $(B$ and $C$ ). Some of the most heavily contacted neurons had a dorsally directed dendrite which could be followed into lamina IV $(E)$. Most lamina V cells which receive ENK contacts were multipolar ( $A$ to $C$ and $E$ ), although bipolar neurons occasionally received contacts $(D)$. The neuron shown in $E$ was sectioned through the nucleus (clear circular area) and appears as a photomicrogaph in Figure $3 C$. The scale bar represents $10 \mu \mathrm{m}$.

laminae I and V receive dense ENK input onto their somata and proximal dendrites. These neurons also may receive ENK input onto their distal dendrites as well. The paucity of ENK contacts on the somata and proximal dendrites of other thalamic projection neurons, especially those located in the deeper laminae, suggests that opiate modulation of this class of projection neurons, if present, only occurs on more distal sites in the dendritic tree.

\section{Discussion}

The present study has identified a major postsynaptic target for opioid modulation in the dorsal horn. Immunocytochemically labeled ENK axonal endings were identified synapsing on retrogradely labeled thalamic projection neurons. The observations were consistent throughout the medullary, cervical, and lumbar dorsal horns of both the cat and monkey. Several 


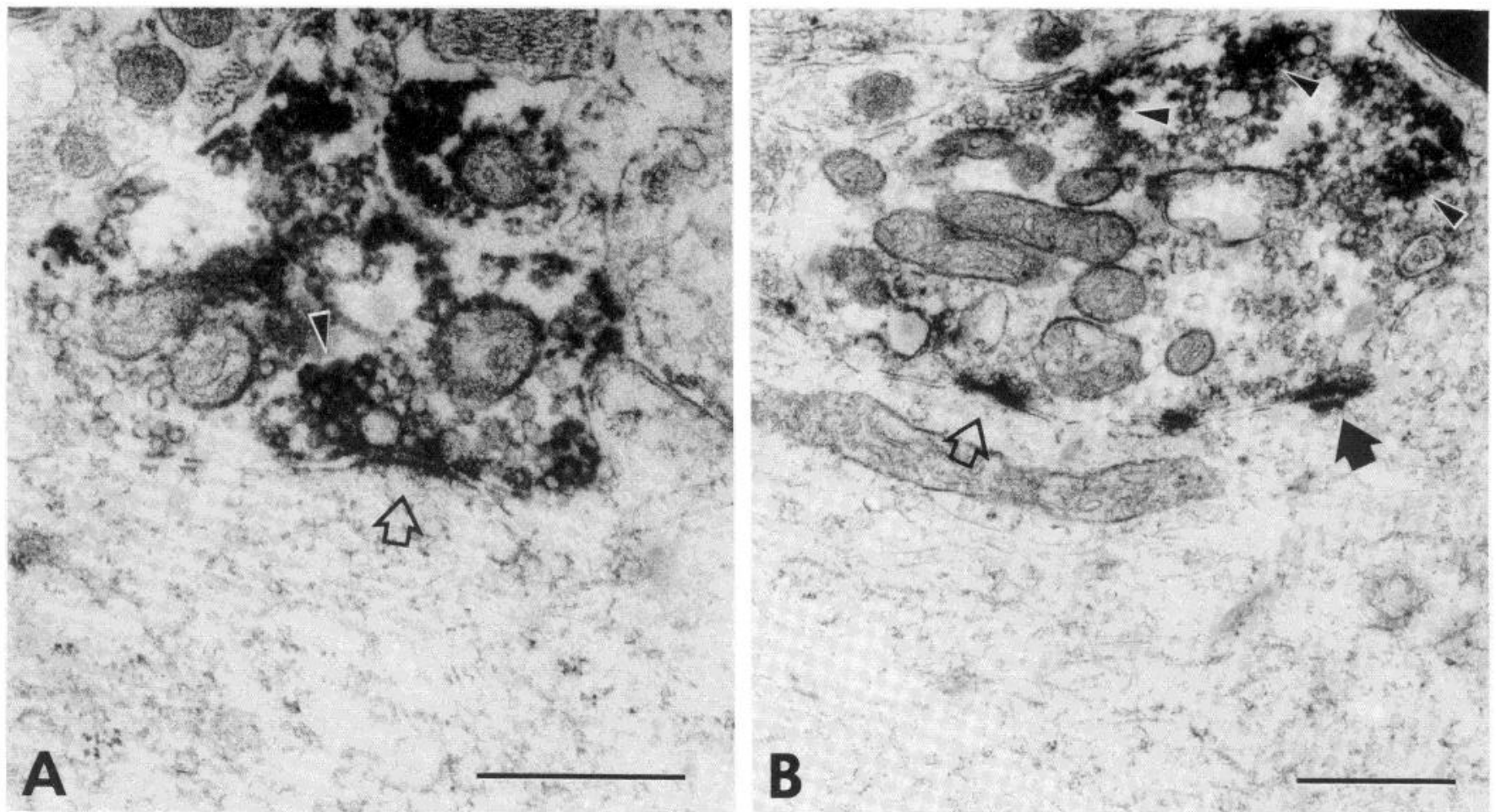

Figure 8. ENK-immunoreactive endings which synapsed on thalamic projection neurons in lamina $\mathrm{V}$ contained mainly round agranular synaptic vesicles. They appeared to form either slightly asymmetrical synaptic contacts (arrow in $A$ ) or an asymmetrical synaptic specialization with a prominent subsynaptic density ( solid arrow in $B$ ). The synaptic specialization was typically small, and in certain large endings more than one synaptic site was found (arrows in $B$ ). The immunocytochemical reaction product was unevenly distributed within the labeled endings, sometimes with dense vesicle accumulation at the synapse (arrowhead in $A$ ), while in other instances the label was concentrated in another part of the varicosity at some distance from the synapse (arrowheads in $B$ ). The ENK-immunoreactive endings in both $A$ and $B$ were taken from lamina $\mathrm{V}$ in the cat MDH. Magnifications $(A) \times 50,700$ and $(B) \times 27,600$. The scale bar represents $0.5 \mu \mathrm{m}$.

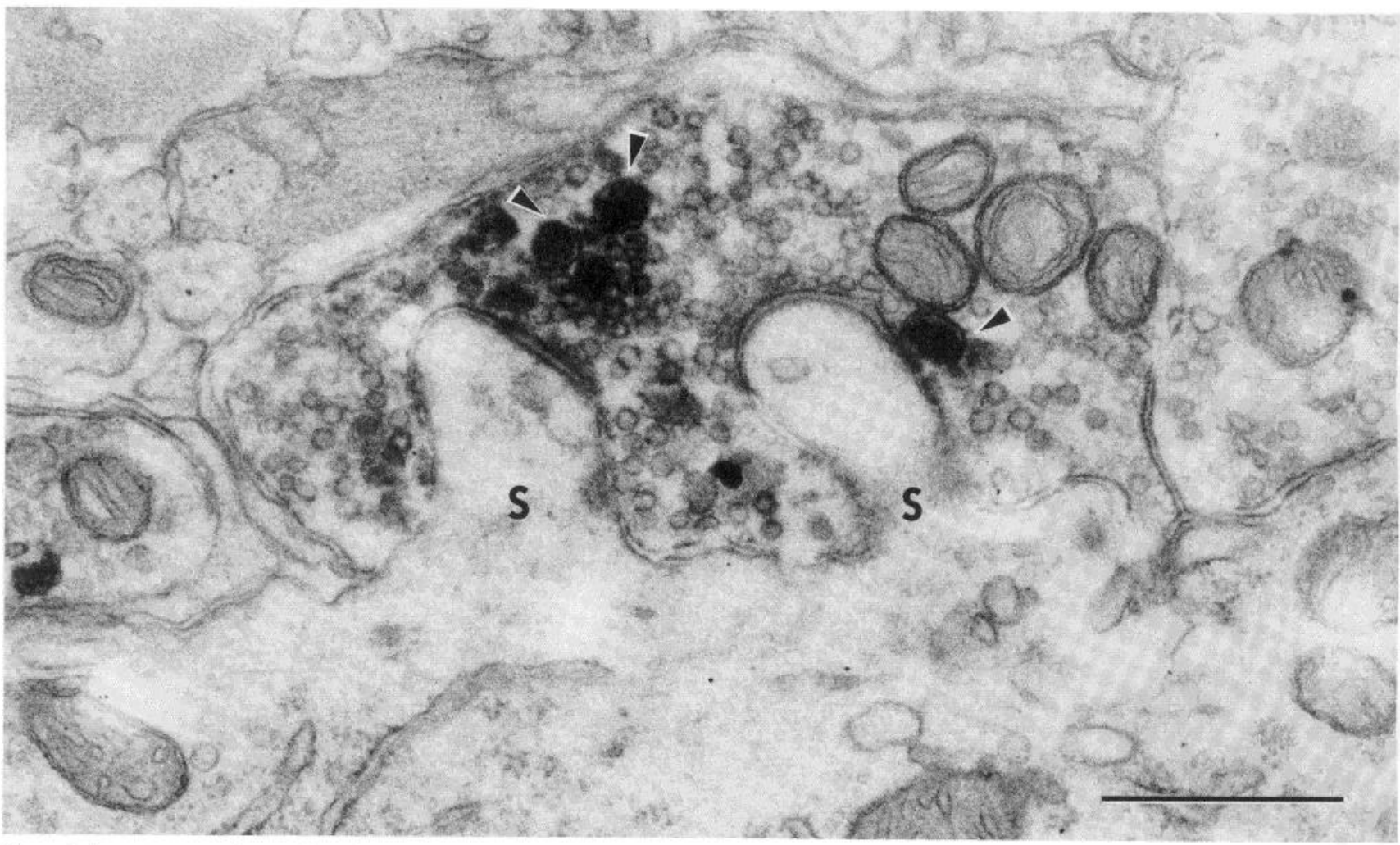

Figure 9. Immunocytochemically labeled ENK ending which synapsed on two somatic spines $(S)$ of a lamina $\mathrm{V}$ thalamic projection neuron in the lumbar enlargement of the monkey. In addition to the round agranular synaptic vesicles, a few dense-core vesicles were present (arrowheads). The immunocytochemical reaction product appeared to be particularly associated with the dense-core vesicles. Magnification $\times 60,450$. The $s c a l e$ bar represents $0.5 \mu \mathrm{m}$. 


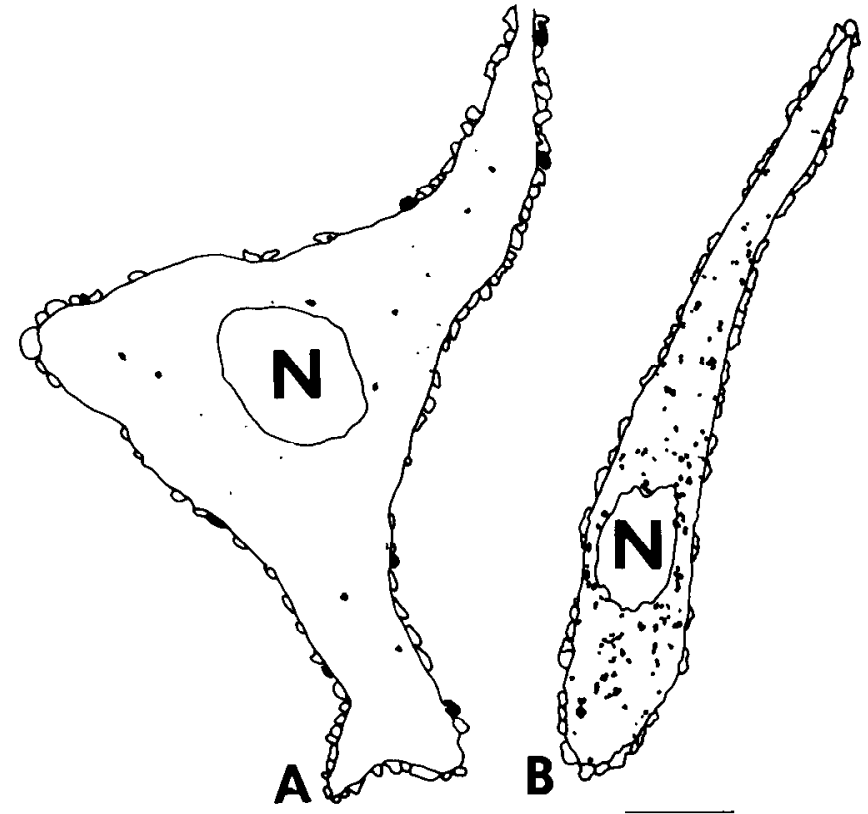

Figure 10. Line drawings of a photomontage reconstruction of a single ultrathin section from two morphologically distinct types of lamina $V$ projection neurons in the cat MDH sectioned in the sagittal plane. Retrograde HRP granules are illustrated within the cell cytoplasm exclusive of the nucleus $(N)$. ENK-immunoreactive axonal endings are blackened, and nonimmunoreactive endings appear in outline. Both the multipolar neuron $(A)$ and the bipolar neuron $(B)$ received numerous synaptic contacts, demonstrating that dense somatic innervation is not limited to a single morphological type of neuron. Eight ENK-immunoreactive contacts occurred on this multipolar neuron in this single ultrathin section, representing $7 \%$ of the contacts on the portion of the cell soma and proximal dendrites shown. A total of 31 ENK-immunoreactive endings in 66 semiserial ultrathin sections were found to synapse on this neuron. No ENK contacts were found on the bipolar neuron $(B)$. The scale bar represents $10 \mu \mathrm{m}$.

observations suggest that there may be functional differences within the class of thalamic projection neurons. The thalamic projection neurons which are most conspicuously contacted by ENK terminals are concentrated in laminae I and V. A striking density of ENK contacts occurs proximally on these neurons. In contrast, thalamic projection neurons in other laminae do not appear to have proximal ENK contacts. However, they may receive ENK contacts more distally, on portions of their dendrites which were not retrogradely labeled.

Within laminae I and V, projection neurons which receive ENK input are not easily divided on the basis of the morphology of their cell bodies. Both large and small, multipolar and bipolar neurons receive ENK contacts. There is a tendency to find more somatic contacts on the larger projection neurons in lamina I, although many small neurons receive numerous ENK contacts on the most proximal portion of their dendrites as they emanate from the cell soma proper. In lamina $\mathrm{V}$, there are more multipolar thalamic projection neurons in our sample than bipolar neurons. These multipolar neurons make up the majority of the projection neurons which receive ENK contacts, especially those with the densest pattern of innervation. However, it is not uncommon to see morphologically similar neurons with patterns of ENK contacts which vary with respect to number and location. The functional significance of the variable ENK contact pattern can only be speculated. Based on previous physiological studies, neurons in each of these categories may be either wide dynamic range or nociceptive-specific. Thus, it is likely that these two classes of nociceptive neurons are modulated by ENK rather than a single physiological class of cell exclusively receiving proximal ENK input.
Validity of double-label experiments. Sequential double labeling of neural elements allows one to address complex issues of neural circuitry which are fundamentally important to all aspects of the nervous system. In designing double-label experiments it is crucial to have a readily distinguishable marker which can be unequivocally localized at the LM and EM level as originating from only one source. Use of retrograde transport to mark neurons is particularly useful since it provides information concerning the axon terminus of the neurons we are studying as well as somatic morphology and location within the neuropil. Immunocytochemical labeling of afferent axons provides identification of neurotransmitters which directly modulate the output of the neuron as well as demonstrating their pattern and density of innervation. At the LM level, the combination of retrograde transport of HRP and immunocytochemistry provides markers which vary with respect to color and size of the labeled profile. At the EM level, the retrograde granules are distinct from the flocculent PAP reaction product which marks the labeled axon terminals. The retrograde marker within neurons is also distinguishable from immunocytochemical label within a cell soma because of its more granular nature as opposed to the flocculent immunocytochemical stain. The retrograde marker can be distinguished from lysozomes and lipofuscin granules by its denser electron opacity which can be readily seen prior to lead staining of the tissue and to a certain extent, even after the lead stain.

Although the distinctive markers make this double-label paradigm particularly attractive to address questions of neural circuitry, some technical aspects limit its usefulness. The retrograde labeling of neurons is limited in that only the soma and proximal dendrites of the labeled neurons contain reaction product, prohibiting analysis of afferent input onto the greatest part of their dendritic arborization. The insoluble, electrondense $D A B$ reaction product provides the least sensitive development of retrograde marker, implying that neurons which contain only a small amount of HRP might be so lightly labeled as to not be readily seen at the LM level.

Immunocytochemical labeling of afferent input has two major constraints: preservation of antigenicity and penetration of the antibody through the tissue section. It is possible that development of the retrograde reaction product in cobalt chloride-intensified $\mathrm{DAB}$ results in some loss of antigenicity. The immunocytochemically stained tissue sections appear to have a somewhat less dense staining pattern in double-labeled as compared to single-labeled material. The decreased immunocytochemical stain might result in an underestimate of the number of afferents which contact a given neuron.

Penetration of the antibodies is a significant problem at both the LM and EM level. At the LM level, a detergent is used for membrane disruption as an aid to penetration. To quantify the frequency of contacts between the labeled elements, the antibody must penetrate the entire section thickness. It appears that $50 \mu \mathrm{m}$ is about the upper limit for penetration in our system. At the EM level, no penetrating agents are used in an effort to preserve membrane structure which has already been compromised by the hydrogen peroxide in the two DAB solutions. Ultrastructurally, antibody labeling is confined to a 1- to $2-\mu \mathrm{m}$ window on the surface of the tissue. In random sectioning of the tissue, few retrogradely labeled neurons occur within the window of immunoreactivity, greatly reducing the likelihood of recovering an immunocytochemically labeled synaptic contact on a given neuron. Thus, it is crucial that part of the retrogradely labeled neuron be on the surface of the tissue. Screening of the tissue at the LM level prior to embedding for EM analysis aids in the recovery of appropriately labeled relationships.

Postsynaptic site of action of enkephalin. A postsynaptic site of action of enkephalin is strongly supported by physiological and morphological evidence. Glutamate-evoked excitation of 
dorsal horn neurons is antagonized by enkephalin, suggesting a postsynaptic action (Zieglgansberger and Tulloch, 1979; Willcockson et al., 1984b). Glutamate produces postsynaptic membrane depolarization associated with an increase in permeability to sodium ions, and this effect is blocked by enkephalin. Enkephalin has no detectable effect on the resting membrane potential or membrane resistance of spinal neurons in vivo or grown in tissue culture (Barker et al., 1978; Zieglgansberger and Tulloch, 1979), although it produces membrane hyperpolarization by increasing the potassium conductance of locus ceruleus and substantia gelatinosa neurons studied in tissue brain slices (Williams et al., 1982; Yoshimura and North, 1983). Thus, enkephalin may alter specific ionic conductances like other transmitters or exert a neuromodulatory role without any direct effects on membrane polarization or ionic conductances.

A postsynaptic role of enkephalin is also supported by its nonspecific inhibitory effects on dorsal horn responses to both non-noxious and noxious stimuli (Duggan et al., 1977; Zieglgansberger and Tulloch, 1979; Willcockson et al., 1984b). The most parsimonious explanation for such nonselective effects on non-noxious and noxious input is that proximally located enkephalin synapses on cell somata and dendrites effectively shunt excitatory input originating on more distal portions of the dendritic tree.

Ultrastructural studies of enkephalin in the dorsal horn indicate that the majority of enkephalin terminals are presynaptic to dendrites in the dorsal horn (Hunt et al., 1980; Aronin et al., 1981; Sumal et al., 1982; Glazer and Basbaum, 1983; LaMotte and deLanerolle, 1983). The present study has revealed that one major postsynaptic target of these enkephalin terminals is thalamic projection neurons in laminac $I$ and $V$. The enkephalin terminals contain mostly round agranular vesicles and are associated with an asymmetrical synaptic specialization at the site of contact with the postsynaptic cell. These findings support the idea that enkephalin is released at such specializations where it binds to opiate receptors on the postsynaptic target.

The evidence for a presynaptic site of action of enkephalin originates mainly from findings of opiate receptors on primary afferent fibers and electrophysiology studies (LaMotte et al., 1976; Jessell and Iversen, 1977; Hiller et al., 1978; MacDonald and Nelson, 1978; Carstens et al., 1979; Mudge et al., 1979; Sastry, 1979; Fields et al., 1980; Nagy et al., 1980; Woolf and Fitzgerald, 1982). However, there is only meager ultrastructural evidence for axoaxonic or dendroaxonic synaptic specializations between enkephalin profiles and primary afferent terminals. In studies in which primary afferent terminals and enkephalin endings are specifically labeled, there is no evidence for synaptic specializations between the two processes (Hunt et al., 1980; Sumal et al., 1982). In single-label studies in which certain profiles are assumed to be primary afferent terminals according to Ralston's (1979) criteria, axoaxonic contacts are extremely rare (Aronin et al., 1981), questionable (LaMotte and deLanerolle, 1983), or not present (Hunt et al., 1980; Glazer and Basbaum, 1983). Enkephalin-containing dendrites shown to receive contacts from profiles of possible primary afferent origin never exhibit specializations in which the enkephalin terminal is presynaptic, even after serial sectioning (Bennett et al., 1982; Glazer and Basbaum, 1983). In view of these findings it is necessary to postulate that enkephalin is not released at sites of synaptic membrane specializations and that it acts by binding to opiate receptors located remote from its site of release. The well documented morphological evidence for enkephalin release at postsynaptic sites of membrane specializations argues against such an hypothesis.

In summary, a morphological substrate for the postsyraptic action of enkephalin exists and is strongly supported by physiological evidence. In contrast, there is still some doubt whether opioid peptides have a presynaptic action at the central terminals of primary afferent neurons in the intact dorsal horn.

Local circuit neurons mediating enkephalin input on thalamic projection neurons. Studies of ENK in the dorsal horn following spinal transections reveal a negligible decrease in ENK immunoreactivity (Seybold and Elde, 1980; Hunt et al., 1981; Ruda et al., 1983), suggesting that most of the ENK in the dorsal horn originates from intrinsic neurons. In cats treated with colchicine to enhance cell body immunoreactivity, many ENK-containing neurons are found in laminae I, II, III, and V (Glazer and Basbaum, 1981; Hunt et al., 1981; Bennett et al., 1982).

ENK-containing neurons in lamina I are distinct from thalamic projection neurons since they are not retrogradely labeled from the thalamus (Basbaum, 1982). The thalamic projection neurons form a thin band superficial to the ENK-containing non-projection neurons (Basbaum, 1982). Lamina I neurons with local axon collaterals are reasonable candidates for the ENK-containing lamina I neurons (Bennett et al., 1981a). Their axon terminals arborize in lamina I among the dendritic arbors of the thalamic projection neurons. A second candidate neuron mediating ENK input on the lamina I projection neurons are lamina II, ENK-containing stalked cells whose axons arborize extensively in lamina I (Bennett et al., 1982). These proposed circuits are exclusively nociceptive (excluding thermoreceptive neurons) since all lamina I neurons and stalked cells respond maximally to noxious input (Willis and Coggeshall, 1978; Bennett et al., 1980. 1981a; Hoffert et al., 1983). Such nociceptive circuits may meciate naloxone-sensitive, long-lasting inhibition of lamina I projection neurons produced by $\mathrm{C}$ fiber strength electrical stimulation in monkeys (Chung et al., 1982). They also may provide the morphological basis for naloxone-sensitive analgesia produced by intense transcutaneous electrical stimulation or acupuncture in humans (Mayer et al., 1976; Sjolund and Eriksson, 1979).

$\Lambda$-beta or $\mathrm{C}$ fiber clectrical stimulation in spinalized animals also produces a naloxone-sensitive inhibition of evoked activity in lamina $\mathrm{V}$ neurons (Woolf and Fitzgerald, 1982) and projection neurons (Chung et al., 1982). These effects may involve ENK-containing non-nociceptive lamina III neurons (Bennett et al., 1981b) or nociceptive lamina $V$ neurons that can provide ENK input to the soma and proximal dendrites of lamina V thalamic projection neurons. Intrinsic ENK-containing neurons in these deeper laminae also may play a role in opioid modulation of nociceptive reflexes in spinal cats and paraplegic humans (Willer and Bussel, 1980; Chung et al., 1983).

Functional implications of ENK input on thalamic projection neurons. Previous studies have shown that iontophoretically administered ENK has predominantly an inhibitory effect on spinal dorsal horn neurons in laminae I and V (Duggan et al., 1977; Randic and Miletic, 1978; Zieglgansberger and Tulloch, 1979; Willcockson et al., 1984b). These laminae are the major terminal zones of nociceptive primary afferents (Light and Perl, 1979; Dubner and Bennett, 1983), and neurons in these locations respond maximally to tissue damaging stimuli, suggesting that ENK plays a prominent role in modulating the output of neurons involved in the transmission of nociceptive information. Directly relevant to the present study are the findings of Willcockson et al. (1984b) that iontophoretically applied ENK inhibits the responses of thalamic projection neurons in monkey laminae I and V to noxious stimulation and to glutamate iontophoresis. Our observations that at least one-third of lamina $I$ and over one-half of lamina $V$ projection neurons receive ENK contacts are consistent with the pharmacological data. ENK contacts were not restricted to a single morphological cell type and, similarly, ENK iontophoresis (Willcockson et al., 1984b) influenced different functional types of neurons in these laminae. 
However, we observed a differential proximal distribution of ENK on projection neurons. The proximal dendrites of some cells received numerous contacts, whereas other cells had few ENK contacts or none at all. The proximal location of ENK on heavily innervated cells suggests that ENK modulates their total output. The likely ENK input on the more distal dendritic arbor may have a more local effect. These projection neurons often receive convergent input from different functional types of primary afferent neurons as well as input from intrinsic local circuit neurons and extrinsic neurons originating from supraspinal structures. We propose that the nonselective inhibition of low threshold and noxious input to many dorsal horn neurons (Duggan et al., 1977; Zieglgansberger and Tulloch, 1979; Willcockson et al., 1984b) by ENK may be related to such a high density of proximal inputs. Since primary afferent input occurs predominantly on dendrites rather than somata (Ralston, 1968, 1979; Ralston and Ralston, 1979), these ENK contacts would be strategically located to suppress the excitatory effects of postsynaptic currents originating on more distal portions of the dendritic tree. In contrast, neurons exhibiting more selective modulation of nociceptive input with minimal effects on nonnoxious inputs may have few proximal ENK contacts.

Thalamic projection neurons heavily innervated by ENK contacts on their somata and proximal dendrites also receive dense input from non-ENK terminals. Since more than onehalf of lamina $\mathrm{V}$ thalamic projection neurons receive either ENK input or 5-hydroxytryptamine (5-HT) input (Ruda and Coffield, 1983) on their somata and proximal dendrites, some cells must receive input from both transmitters. Similar to ENK, iontophoretically administered 5-HT also has predominantly an inhibitory effect on projection neurons (Jordan et al., 1979; Willcockson et al., 1984a). In addition, some of the non-ENK terminals contacting thalamic projection neurons may arise from other descending inhibitory pathways known to project to the dorsal horn (see Dubner and Bennett, 1983, for review). All of these findings suggest that more than one pharmacologically distinct inhibitory system synapses on the somata and proximal dendrites of some thalamic projection neurons.

Most of the large multipolar thalamic projection neurons in lamina $\mathrm{V}$ likely are wide dynamic range or nociceptive-specific neurons. We propose that the responses of these neurons are subject to considerable modulation by ENK and other transmitters and that this modulation may be related to behavioral contingencies such as attention, stimulus relevance, and motivation (Dubner et al., 1981; Hayes et al., 1981). Medullary dorsal horn projection neurons in lamina $\mathrm{V}$ studied in the awake monkey exhibit behaviorally related as well as sensorydiscriminative responses. Some precisely code stimulus features, others respond only to behaviorally important stimuli and are not sensitive to stimulus features, while others exhibit both sensory coding and behaviorally related activity (Dubner et al., 1981; Hayes et al., 1981; Bushnell et al., 1984). Large multipolar projection neurons with convergent primary afferent, intrinsic, and descending input are logical candidates for neurons involved in coding this behavioral information.

It is an oversimplification to conclude that these pharmacologically defined systems are only involved in analgesic mechanisms. ENK and 5-HT contacts are found on some dorsul horn projection neurons that receive input exclusively from low threshold mechanoreceptors and presumably are not involved in nociception (Dubner et al., 1983). In addition, ENK-containing intrinsic dorsal horn neurons that provide input to projection neurons also participate in segmental reflex activity (Woolf et al., 1980; Chung et al., 1982, 1983). There also are reports that opioid peptides have effects on learning and memory processes that may involve spinal enkephalins (Koob and Bloom, 1982). Other evidence indicates that 5-HT pathways produce increased motor neuron excitability and enhance organized motor behaviors associated with various stages of arousal (Trulson and Jacobs, 1979; Vandermaelen and Aghajanian, 1982). It seems reasonable to propose that in preparation for such organized and learned motor behaviors, spinal circuits involving different neural transmitters produce suppression of extraneous, incoming sensory signals and segmental reflexes, thereby aiding an animal to extract behaviorally relevant information from its environment.

\section{References}

Adams, J. C. (1977) Technical considerations on the use of horseradish peroxidase as a neuronal marker. Neuroscience 2: 141-145.

Aronin, N., M. Difiglia, A. S. Liotta, and J. B. Martin (1981) Ultrastructural localization and biochemical features of immunoreactive Leu-enkephalin in monkey dorsal horn. J. Neurosci. 1: 561-577.

Barker, J. L., J. H. Neale, T. G. Smith, Jr., and R. L. McDonald (1978) Opiate peptide modulation of amino acid responses suggests novel form of neuronal communication. Science 199: 1451-1453.

Basbaum, A. (1982) Anatomical substrates for the descending control of nociception. In Brain Stem Control of Spinal Mechanisms, B. Sjoland and A. Bjorklund, eds., pp. 119-133, Elsevier-North Holland Publishing Co., Amsterdam.

Bennett, G. J., M. Abdelmoumene, H. Hayashi and R. Dubner (1980) Physiology and morphology of substantia gelatinosa neurons intracellularly stained with horseradish peroxidase. J. Comp. Neurol. 194: 809-827.

Bennett, G. J., M. Abdelmoumene, H. Hayashi, M. J. Hoffert, and R. Dubner (1981a) Spinal cord layer I neurons with axon collaterals that generate local arbors. Brain Res. 209: 421-426.

Bennett, G. J., M. Abdelmoumene, H. Hayashi, M. J. Hoffert, M. A. Ruda, and R. Dubner (1981b) Physiology, morphology and immunocytology of dorsal horn layer III neurons. Pain (Suppl.) 1: S240.

Bennett, G. J., M. A. Ruda, S. Gobel, and R. Dubner (1982) Enkephalin immunoreactive stalked cells and lamina IIb islet cells in cat substantia gelatinosa. Brain Res. 240: 162-166.

Burton, H., and A. D. Craig, Jr. (1979) Distribution of trigeminothalamic projection cells in cat and monkey. Brain Res. 161: 515-521.

Bushnell, M. C., G. H. Duncan, R. Dubner, and L. F. He (1984) Activity of trigeminothalamic neurons in medullary dorsal horn of awake monkeys trained in a thermal discrimination task. J. Neurophysiol. 52: $170-187$.

Carstens, E., and D. L. Trevino (1978) Laminar origins of spinothalamic projections in the cat as determined by the retrograde transport of horseradish peroxidase. J. Comp. Neurol. 182: 151-166.

Carstens, E., I. Tulloch, W. Zieglgansberger, and M. Zimmermann (1979) Presynaptic excitability changes induced by morphine in single cutaneous afferent C- and A-fibers. Pflugers Arch. 379: 143147.

Chung, J. M., Z. R. Fang, C. Cargill, and W. D. Willis (1982) Inhibition of primate spinothalamic cells by peripheral nerve stimulation. Am. Pain Soc. Abstr., p. 6.

Chung, J. M., Z. R. Fang, C. L. Cargill, and W. D. Willis (1983) Prolonged, naloxone-reversible inhibition of the flexion reflex in the cat. Pain 15: 35-53.

Dubner, R., and G. J. Bennett (1983) Spinal and trigeminal mechanisms of nociception. Annu. Rev. Neurosci. 6: 381-418.

Dubner, R., D. S. Hoffman, and R. L. Hayes (1981) Neuronal activity in medullary dorsal horn of awake monkeys trained in a thermal discrimination task. III. Task-related responses and their functional role. J. Neurophysiol. 46: 444-464.

Dubner, R., M. A. Ruda, V. Miletic, M. J. Hoffert, G. J. Bennett, N. Nishikawa, and J. Coffield (1984) Neural circuitry mediating nociception in the medullary and spinal dorsal horns. In Advances in Pain Research and Therapy. Vol. 6: Neural Mechanisms of Pain, L. Kruger and J. C. Liebeskind, eds., pp. 151-166, Raven Press, New York.

Duggan, A. W., J. G. Hall, and P. M. Headley (1977) Enkephalins and dorsal horn neurones of the cat: Effects on responses to noxious and innocuous skin stimuli. Br. J. Pharmacol. 61: 399-408.

Fields, H. L., P. C. Fmson, B. K. Leigh, R. F. T. Gilbert, and L. L. Iverson (1980) Multiple opiate receptor sites on primary afferent fibers. Nature 284: 351 . 
Fishbach, G. D., K. Dunlap, A. Mudge, and S. Leeman (1981) Peptide and amine transmitter effect on embryonic chick sensory neurons in vitro. In Neurosecretion and Brain Peptides, J. B. Martin, S. Reichlin, and K. L. Bick, eds., pp. 175-188, Raven Press, New York.

Giesler, G. J., Jr., D. Menetrey, G. Guilbaud, and J. M. Besson (1976) Tumbar cord neurons at the origin of the spinothalamic tract in the rat. Brain Res. 118: 320-324.

Giesler, G. J., Jr., D. Menetrey, and A. I. Basbaum (1979) Differential origins of spinothalamic tract projections to medial and lateral thalamus in the rat. J. Comp. Neurol. 184: 107-126.

Glazer, E. J., and A. I. Basbaum (1981) Immunohistochemical localization of leucine-enkephalin in the spinal cord of the cat: Enkephalin-containing marginal neurons and pain modulation. J. Comp. Neurol. 196: 377-389.

Glazer, E., and A. I. Basbaum (1983) Opioid neurons and pain modulation: An ultrastructural analysis of enkephalin in cat superficial dorsal horn. Neuroscience 10: 357-376.

Hayes, R. L., R. Dubner, and D. S. Hoffman (1981) Neuronal activity in medullary dorsal horn of awake monkeys trained in a thermal discrimination task. II. Behavioral modulation of responses to thermal and mechanical stimuli. J. Neurophysiol. 46: 428-443.

Hiller, J. M., E. J. Simon, S. M. Crain, and E. R. Peterson (1978) Opiate receptors in cultures of fetal mouse dorsal root ganglia (DRG) and spinal cord: Predominance in DRG neurites. Brain Res. 145 396-400.

Hockfield, S., and S. Gobel (1978) Neurons in and near nucleus caudalis with long ascending projection axons demonstrated by retrograde labeling with horseradish peroxidase. Brain Res. 139: 333-339.

Hoffert, M. J., V. Miletic, M. A. Kuda, and K. Dubner (1983) Immunocytochemical identification of serotonin axonal contacts on characterized neurons in laminae I and II of the cat dorsal horn. Brain Res. 267: 361-364.

Hokfelt, T., A. Ljungdahl, L. Terenius, R. Elde, and G. Nilsson (1977) Immunohistochemical analysis of peptide pathways possibly related to pain and analgesia: Enkephalin and substance P. Proc. Natl. Acad. Sci. U. S. A. 74: 3081-3085.

Hunt, S. P., J. S. Kelly, and P. C. Emson (1980) The electron microscopic localization of methionine-enkephalin within the superficial layers (I and II) of the spinal cord. Neuroscience 5: 1871-1890.

Hunt, S. P., J. S. Kelly, P. C. Emson, J. R. Kimmel, R. J. Miller, and J. Y. Wu (1981) An immunohistochemical study of neuronal populations containing neuropeptides or gamma-aminobutyrate within the superficial layers of the rat dorsal horn. Neuroscience 6: 18831898.

Jessell, T. M., and L. L. Iversen (1977) Opiate analgesics inhibit substance $\mathrm{P}$ release from rat trigeminal nucleus. Nature 268: 549 551.

Jordan, L. M., D. R. Kenshalo, Jr., R. F. Martin, L. H. Haber, and W. D. Willis (1979) Two populations of spinothalamic tract neurons with opposite responses to 5-hydroxytryptamine. Brain Res. 164: $342-346$.

Kenshalo, D. R. Jr., R. B. Leonard, J. M. Chung, and W. D. Willis (1979) Responses of primate spinothalamic neurons to graded and to repeated noxious heat stimuli. J. Neurophysiol 42: 1370-1389.

Koob, G. F., and F. E. Bloom (1982) Behavioral effects of neuropeptides: Endorphins and vasopressin. Annu. Rev. Physiol. 44: 571-582.

LaMotte, C. C., and N. C. deLanerolle (1983) Ultrastructure of chemically defined neuron systems in the dorsal horn of the monkey. II. Methionine-enkephalin immunoreactivity. Brain Res. 274: 51-63.

LaMotte, C., C. B. Pert, and S. H. Snyder (1976) Opiate receptor binding in primate spinal cord: Distribution and changes after dorsal root section. Brain Res. 112: 407-412.

LaVail, J. H., and M. A. LaVail (1975) The retrograde intraaxonal transport of horseradish peroxidase in the chick visual system: A light and electron microscopic study. J. Comp. Neurol. 157: 303-358.

Light, A. R., and E. R. Perl (1979) Spinal termination of functionally identified primary afferent neurons with slowly conducting myeli nated fibers. J. Comp. Neurol. 186: 133-150.

MacDonald, R. L., and P. G. Nelson (1978) Specific-opiate-induced depression in transmitter release from dorsal root ganglion cells in culture. Science 199: 1449-1451.

Mayer, D. J., D. D. Price, J. Barber, and A. Rafii (1976) Acupuncture analgesia: Evidence for activation of a pain inhibitory system as a mechanism of action. In Advances in Pain Research and Therapy, J. J. Bonica and D. Albe-Fessard, eds., Vol. 1, pp. 751-754, Raven
Press, New York.

Mudge, A. W., S. Leeman, and G. D. Fishback (1979) Enkephalin inhibits release of substance $P$ from sensory neurons in culture and decreases action potential duration. Proc. Natl. Acad. Sci. U. S. A. 76: $526-530$.

Nagy, J. I., S. R. Vincent, W. A. Staines, H. C. Fibiger, T. D. Reisine, and H. I. Yamamura (1980) Neurotoxic action of capsaicin on spinal substance $\mathrm{P}$ neurons. Brain Res. 186: 435-444.

Price, D. D., R. Dubner, and J. W. Hu (1976) Trigeminothalamic neurons in nucleus caudalis responsive to tactile, thermal, and nociceptive stimulation of monkey's face. J. Neurophysiol. 39: 936-953.

Price, D. D., H. Hayashi, R. Dubner, and M. A. Ruda (1979) Functional relationships between neurons of marginal and substantia gelatinosa layers of primate dorsal horn. J Neurophysiol. 42: 1590-1608.

Ralston, H. J. III (1968) Dorsal root projection to dorsal horn neurons in the cat spinal cord. J. Comp. Neurol. 132: 303-330.

Ralston, H. J., III (1979) The fine structure of laminae I, II and III of the macaque spinal cord. J. Comp. Neurol. 184: 619-642.

Ralston, H. J., III, and D. D. Ralston (1979) The distribution of dorsal root axons in laminae I, II, and III of the macaque spinal cord: A quantitative electron microscope study. J. Comp. Neurol. 184: 643684.

Randic, M., and V. Miletic (1978) Depressant actions of methionineenkephalin and somatostatin in cat dorsal horn neurones activated by noxious stimuli. Brain Res. 152: 196-202.

Ruda, M. A. (1982) Opiates and pain pathways: Demonstration of enkephalin synapses on dorsal horn projection neurons. Science 215 : $1523-1525$

Kuda, M. A., and J. Coffield (1983) Light and ultrastructural immunocytochemical localization of serotonin synapses on primate spinothalamic tract neurons. Soc. Neurosci. Abstr. 9: 1.

Ruda, M. A., J. Coffield, G. J. Bennett, and R. Dubner (1983) Role of serotonin (5-HT) and enkephalin (ENK) in trigeminal and spinal pain pathways. J. Dental Res. 62: 691

Sar, M., W. E. Stumpf, R. J. Miller, K. J. Chang, and P. Cuatrecasas (1978) Immunohistochemical localization of enkephalin in rat brain and spinal cord. J. Comp. Neurol. 182: 17-38.

Sastry, B. R. (1979) Presynaptic effects of morphine and methionineenkephalin in feline spinal cord. Neuropharmacology 18: 367-375.

Satoh, M., S. Kawajiri, Y. Ukai, and M. Yamamoto (1979) Selective and nonselective inhibition by enkephalins and noradrenaline of nociceptive response of lamina $\mathrm{V}$ type neurons in the spinal dorsal horn of the rabbit. Brain Res. 177: 384-387.

Seybold, V., and R. Elde (1980) Immunohistochemical studies of peptidergic neurons in the dorsal horn of the spinal cord. J. Histochem. Cytochem. 28: 367-370.

Sjolund, B. H., and M. B. E. Eriksson (1979) The influence of naloxone on analgesia produced by peripheral conditioning stimulation. Brain Res. 178: 295-302.

Snider, R. S., and J. C. Lee (1961) A Stereotaxic Atlas of the Monkey Brain (Macaca mulatta), The University of Chicago Press, Chicago.

Snider, R. S., and W. T. Niemer (1961) A Stereotaxic Atlas of the Cat Brain, The University of Chicago Press, Chicago.

Sternberger, L. A. (1979) Immunocytochemistry, Ed. 2, John Wiley \& Sons, New York

Sumal, K. K., V. M. Pickel, R. J. Miller, and D. J. Reis (1982) Enkephalin-containing neurons in substantia gelatinosa of spinal trigeminal complex: Ultrastructure and synapse interaction with primary sensory afferents. Brain Res. 248: 223-236.

Trevino, D. L., R. A. Maunz, R. N. Bryan, and W. D. Willis (1972) Location of cells of origin of the spinothalamic tract in the lumbar enlargement of cat. Exp. Neurol. 34: 64-77.

Trulson, M. E., and B. J. Jacobs (1979) Raphe unit activity in freely moving cats: Correlation with level of behavior arousal. Brain Res. 163: 135-150.

Uhl, G. R., R. R. Goodman, M. J. Kuhar, S. R. Children, and S. H. Snyder (1979) Immunohistochemical mapping of enkephalin containing cell bodies, fibers and nerve terminals in the brain stem of the rat. Brain Res 166: 75-94.

Vandermaelen, C. P., and G. K. Aghajanian (1982) Serotonin-induced depolarization of rat facial motoneurons in vivo: Comparison with amino acid transmitters. Brain Res. 239: 139-152.

Willcockson, W. S., J. M. Chung, Y. Hori, K. H. Lee, and W. D. Willis (1984a) Effects of iontophoretically released amino acids and amines on primate spinothalamic tract cells. J. Neurosci. 4: 732-740. 
Willcockson, W. S., J. M. Chung, Y. Hori, K. H. Lee, and W. D. Willis (1984b) Effects of iontophoretically released peptides on primate spinothalamic tract cells. J. Neurosci. 4: 741-750.

Willer, J. C., and B. Bussel (1980) Evidence for a direct spinal mechanism in morphine-induced inhibition of nociceptive reflexes in humans. Brain Res. 187: 212-215.

Williams, J. T., T. M. Egan, and R. A. North (1982) Enkephalin opens potassium channels on mammalian central neurones. Nature 299: 74-77.

Willis, W. D., and R. E. Coggeshall (1978) Sensory Mechanisms of the Spinal Cord, Plenum Press, New York.

Willis, W. D., D. L. Trevino, J. D. Coulter, and R. A. Maunz (1974) Responses to primate spinothalamic tract neurons to natural stimulation of hindlimb. J. Neurophysiol. 37: 358-372.

Willis, W. D., D. R. Kenshalo, Jr., R. B. Leonard (1979) The cells of origin of the primate spinothalamic tract. J. Comp. Neurol. 188:
$543-574$.

Woolf, C. J., and M. Fitzgerald (1982) Do opioid peptides mediate a presynaptic control of C-fibre transmission in the rat spinal cord? Neurosci. Lett. 29: 67-72.

Woolf, C. J., D. Mitchell, and G. D. Barrett (1980) Antinociceptive effect of peripheral segmental electrical stimulation in the rat. Pain 8: 237-252.

Yaksh, T. L., S. P. Huang, and T. A. Rudy (1977) The direct and specific opiate-like effect of Met-enkephalin and analogues on the spinal cord. Neuroscience 2: 593-596.

Yoshimura, M., and R. A. North (1983) Substantia gelatinosa neurones hyperpolarized in vitro by enkephalin. Nature 305: 529-530

Zieglgansberger, W., and I. F. Tulloch (1979) The effects of methionineand leucine-enkephalin on spinal neurones of the cat. Brain Res. 167: 53 64. 